\title{
Endoscopic biliary stenting: indications, choice of stents, and results: European Society of Gastrointestinal Endoscopy (ESGE) Clinical Guideline - Updated October 2017
}

Authors

Jean-Marc Dumonceau ${ }^{1}$, Andrea Tringali², Ioannis S. Papanikolaou ${ }^{3}$, Daniel Blero ${ }^{4}$, Benedetto Mangiavillano ${ }^{5}$, Arthur Schmidt $^{6}$, Geoffroy Vanbiervliet ${ }^{7}$, Guido Costamagna ${ }^{8}$, Jacques Devière ${ }^{9}$, Jesús García-Cano ${ }^{10}$, Tibor Gyökeres ${ }^{11}$, Cesare Hassan ${ }^{12}$, Frédéric Prat ${ }^{13}$, Peter D. Siersema ${ }^{14}$, Jeanin E. van Hooft ${ }^{15}$

Institutions

1 Gedyt Endoscopy Center, Buenos Aires, Argentina

2 Digestive Endoscopy Unit, Catholic University, Rome, Italy

3 Hepatogastroenterology Unit, Second Department of Internal Medicine - Propaedeutic, Research Institute and Diabetes Center, Medical School, National and Kapodistrian University, Attikon University General Hospital, Athens, Greece

4 CHU Charleroi et Vésale, ISPPC, Charleroi, Belgium

5 Gastrointestinal Endoscopy Unit, Humanitas Mater Domini, Castellanza, Italy - Humanitas University, Milan, Italy

6 Department of Gastroenterology, Klinikum Ludwigsburg, University of Heidelberg, Germany

7 Department of Gastroenterology and Endoscopy, Hôpital Universitaire l'Archet, Nice, France

8 Digestive Endoscopy Unit Catholic University, Rome, Italy

9 Department of Gastroenterology Hepatopancreatology, and Digestive Oncology, Erasme University Hospital, Université Libre de Bruxelles, Brussels, Belgium

10 Department of Digestive Diseases, Hospital Virgen de La Luz, Cuenca, Spain

11 Department of Gastroenterology, Medical Center, Hungarian Defense Forces, Budapest, Hungary

12 Digestive Endoscopy Unit, Catholic University, Rome, Italy

13 Gastroenterology Unit, Hôpital Cochin (AP-HP), Paris, France

14 Department of Gastroenterology and Hepatology, Radboud University Medical Center, Nijmegen, The Netherlands

15 Department of Gastroenterology and Hepatology, Amsterdam UMC, University of Amsterdam, The Netherlands
Bibliography

DOI https://doi.org/10.1055/a-0659-9864

Published online: 7.8.2018 | Endoscopy 2018; 50: 910-930

(c) Georg Thieme Verlag KG Stuttgart · New York

ISSN 0013-726X

Corresponding author

Jean-Marc Dumonceau, MD PhD, Gedyt Endoscopy Center, Beruti 2347 (C1117AAA), Buenos Aires, Argentina

Fax: +54-11-5288-6100

jmdumonceau@hotmail.com

\# Appendix e1, Tables e1-e5

Online content viewable at:

https://doi.org/10.1055/a-0659-9864

\section{MAIN RECOMMENDATIONS}

ESGE recommends against routine preoperative biliary drainage in patients with malignant extrahepatic biliary obstruction; preoperative biliary drainage should be reserved for patients with cholangitis, severe symptomatic jaundice (e.g., intense pruritus), or delayed surgery, or for before neoadjuvant chemotherapy in jaundiced patients.

Strong recommendation, moderate quality evidence.

ESGE recommends the endoscopic placement of a 10-mm diameter self-expandable metal stent (SEMS) for preoperative biliary drainage of malignant extrahepatic biliary obstruction.

Strong recommendation, moderate quality evidence.

ESGE recommends SEMS insertion for palliative drainage of of extrahepatic malignant biliary obstruction.

Strong recommendation, high quality evidence.

ESGE recommends against the insertion of uncovered SEMS for the drainage of extrahepatic biliary obstruction of unconfirmed etiology.

Strong recommendation, low quality evidence. 
ESGE suggests against routine preoperative biliary drainage in patients with malignant hilar obstruction.

Weak recommendation, low quality evidence.

ESGE recommends uncovered SEMSs for palliative drainage of malignant hilar obstruction.

Strong recommendation, moderate quality evidence.
ESGE recommends temporary insertion of multiple plastic stents or of a fully covered SEMS for treatment of benign biliary strictures.

Strong recommendation, moderate quality evidence.

ESGE recommends endoscopic placement of plastic stent(s) to treat bile duct leaks that are not due to transection of the common bile duct or common hepatic duct.

Strong recommendation, moderate quality evidence.

$\begin{array}{ll}\text { ABBREVIATIONS } \\ \text { ABS } & \text { anastomotic biliary stricture } \\ \text { ASA } & \text { American Society of Anesthesiologists } \\ \text { BBS } & \text { benign biliary stricture } \\ \text { CBD } & \text { common bile duct } \\ \text { CI } & \text { confidence interval } \\ \text { CRP } & \text { C-reactive protein } \\ \text { DDLT } & \text { deceased donor liver transplantation } \\ \text { EBS } & \text { endoscopic biliary sphincterotomy } \\ \text { ERCP } & \text { endoscopic retrograde cholangiopancreato- } \\ & \text { graphy } \\ \text { ESGE } & \text { European Society of Gastrointestinal Endoscopy } \\ \text { EUS-BD } & \text { endoscopic ultrasonography-guided biliary } \\ & \text { drainage } \\ \text { Fr } & \text { French } \\ \text { FCSEMS } & \text { fully covered self-expandable metal stent } \\ \text { HR } & \text { hazard ratio } \\ \text { LAMS } & \text { lumen-apposing metal stent } \\ \text { LDLT } & \text { living donor liver transplantation } \\ \text { MRI } & \text { magnetic resonance imaging } \\ \text { MPS } & \text { multiple plastic stents } \\ \text { MHS } & \text { malignant hilar stricture } \\ \text { OR } & \text { odds ratio } \\ \text { PET } & \text { positron emission tomography } \\ \text { PBD } & \text { preoperative biliary drainage } \\ \text { PCSEMS } & \text { partially covered self-expandable metal stent } \\ \text { PTBD } & \text { percutaneous transhepatic biliary drainage } \\ \text { RCT } & \text { randomized controlled trial } \\ \text { SEMS } & \text { self-expandable metal stent } \\ \text { WHO } & \text { World Health Organization } \\ \text { WMD } & \text { weighted mean difference } \\ & \end{array}$

This Guideline is an official statement of the European Society of Gastrointestinal Endoscopy (ESGE). It addresses the indications for and results of biliary stenting as well as the choice of stent.

\section{Introduction}

The Clinical Guideline on biliary stenting published in 2012 by the European Society of Gastrointestinal Endoscopy (ESGE) made recommendations on the indications and choice of stents for benign and malignant biliary conditions [1]. New evidence has become available since then and is discussed in the present update, and new recommendations are issued. The associated Technology Review that described the models of biliary stents available and the stenting techniques, including advanced techniques such as insertion of multiple plastic stents (MPS), drainage of hilar strictures, retrieval of migrated stents, and combined stenting in patients with both malignant biliary and duodenal obstruction, is considered up-to-date and will be revised when appropriate [2].

\section{Methods}

ESGE commissioned this Guideline and appointed a guideline leader (J.M.D.) who invited the listed authors to participate in the project development. The key questions were prepared by the coordinating team (J.M.D., A.T., C.H.) and then approved by the other members. The coordinating team formed task force subgroups, each with its own leader, who was assigned key questions (see Appendix e1, available online in Supplementary material).

Each task force performed a systematic literature search to prepare evidence-based and well-balanced statements on their assigned key questions. The literature search was performed using MEDLINE and Embase to identify new publications since January 2011 published in English, focusing on meta-analyses and fully published prospective studies, particularly randomized controlled trials (RCTs), performed in humans. Retrospective analyses and pilot studies were also included if they addressed topics not covered in the prospective studies. The Grading of Recommendations Assessment, Development and Evaluation (GRADE) system was adopted to define the strength of recommendation and the quality of evidence [3,4]. Each task force proposed statements on their assigned key questions which were discussed during a meeting in Dusseldorf, Germany in February 2016. Literature searches were re-run in July 2017. This time-point should be the starting point in the search for new evidence for future updates to this guideline. In December 2017 a draft prepared by J.M.D., A.T., and J.V.H. was sent to all group members for review. The draft was also reviewed by two 
members of the ESGE Governing Board, by external reviewers and then sent for further comments to the ESGE National Societies and Individual Members. After agreement on a final version, the manuscript was submitted to the journal Endoscopy for publication. All authors agreed on the final revised version.

This Guideline was issued in 2018 and will be considered for review in 2022, or sooner if new and relevant evidence becomes available. Any updates to the Guideline in the interim period will be noted on the ESGE website: http://www.esge. com/esge-guidelines.html.

\section{Malignant extrahepatic biliary obstruction}

\subsection{Indications for biliary stenting}

\subsubsection{Preoperative biliary drainage}

\section{RECOMMENDATION}

ESGE recommends against routine preoperative biliary drainage in patients with malignant extrahepatic biliary obstruction; preoperative biliary drainage should be reserved for patients with cholangitis, severe symptomatic jaundice (e.g., intense pruritus), or delayed surgery, or for before neoadjuvant chemotherapy in jaundiced patients.

Strong recommendation, moderate quality evidence.

\section{RECOMMENDATION}

ESGE recommends the endoscopic placement of a 10$\mathrm{mm}$ diameter self-expandable metal stent (SEMS) for preoperative biliary drainage of extrahepatic malignant biliary obstruction.

Strong recommendation, moderate quality evidence.

Preoperative biliary drainage (PBD) is common practice: a US administrative database study (2573 patients with pancreaticoduodenectomy) found that the PBD rate increased from $30 \%$ to $59 \%$ of patients between 1995 and 2007, with the majority of PBD occurring prior to surgical consultation [5]. Neoadjuvant therapy is increasingly used before surgery for pancreatic adenocarcinoma and it often requires PBD ( $58 \%$ of 199 patients in a prospective database) [6].

Among 10 unique meta-analyses that assessed the potential benefit of PBD in patients with a distal biliary obstruction ( $\vee$ Table e1, available online in Supplementary material), none found differences in terms of mortality and, with respect to morbidity, 9 found it to be similar [7-12] or higher [13-15] with vs. without PBD; a single study reported a lower morbidity (serious adverse events) with vs. without PBD [16]. Although the meta-analyses were limited by the characteristics of the original studies, including selection bias, the use of the percutaneous or the endoscopic route for PBD, and the inclusion in some studies of patients with proximal biliary obstruction, they represent the best available evidence. Of note, two retro- spective studies that compared PBD vs. no PBD in a total of 170 patients reported an independent association between endoscopic PBD and shorter patient survival $[17,18]$.

Apart from well-accepted indications for PBD such as cholangitis, severe jaundice was suggested to be an adequate indication: a recent, mostly retrospective, study (1200 patients) found that a total serum bilirubin $\geq 300 \mu \mathrm{mol} / \mathrm{L}$ was associated with a high risk of severe postoperative complications [19]. Of note, patients with a total serum bilirubin $\geq 250 \mu \mathrm{mol} / \mathrm{L}$ were excluded from the largest RCT of PBD vs. no PBD [20]. On the other hand, a retrospective matched case-control study (152 patients) suggested that even in patients with relatively severe jaundice (bilirubin $\geq 15 \mathrm{mg} / \mathrm{dL}[256 \mu \mathrm{mol} / \mathrm{L}]$ ) classified as grade 2 on the American Society of Anesthesiologists (ASA) scale, PBD presented no advantage [21]. Thus, the validity of severe jaundice as an indication for PBD remains unclear.

If a decision is made to proceed with PBD in patients with malignant distal biliary obstruction who are undergoing curative resection, the endoscopic route is preferred over the percutaneous route because data from three retrospective series with long-term follow-up that compared the two approaches (total, 1213 patients) showed longer patient survival and less frequent peritoneal/liver recurrence in the endoscopic groups [22-24].

With respect to the use of plastic stents vs. self-expandable metal stents (SEMSs) for PBD, a meta-analysis (four retrospective and one prospective cohorts; total, 704 patients) found that SEMSs were associated with a lower rate of endoscopic reintervention (3.4\% vs. $14.8 \%$ ) and no difference in overall surgical morbidity or mortality [25]. The interval between biliary drainage and surgery was not reported but we calculated that neoadjuvant therapy, an indicator of long PBD duration, was performed in 337 (48\%) patients. In a more recent multicenter RCT (86 patients) comparing plastic stents and fully covered SEMSs (FCSEMSs) there were similar outcomes including need for reintervention, surgery-related adverse events, and mortality, but the interval between biliary drainage and surgery was only 13 days [26].

In the setting of neoadjuvant therapy, an RCT (54 patients) found that use of FCSEMSs resulted in a longer stent patency duration and fewer days of delay in neoadjuvant therapy compared with plastic stents and uncovered SEMSs; total costs associated with PBD were similar for all stent models [27]. Similarly, two retrospective studies (total, 72 patients) found that, compared with SEMSs, plastic stents were associated with more complications; one of the studies also analyzed the delay in neoadjuvant therapy and costs: with SEMSs, the delay was shorter and the total costs were similar [28,29]. The type of SEMS was stated in one study only (FCSEMS) [29]. FCSEMSs also present the advantage of being removable if surgical resection is finally not performed.

Finally, SEMSs do not compromise R0 resection or increase the risk of local unresectability according to a retrospective analysis of 593 patients [30], but the presence of a biliary plastic stent or SEMS prolongs operative duration [21,30]. 


\subsubsection{Palliative biliary drainage}

\subsubsection{Route for primary biliary drainage}

RECOMMENDATION

ESGE recommends that decompression of malignant extrahepatic biliary obstruction be performed via endoscopic retrograde cholangiopancreatography (ERCP) rather than by surgery or percutaneously.

Strong recommendation, moderate quality evidence.

ESGE recommends restricting the use of EUS-guided biliary drainage to cases where biliary drainage using standard ERCP techniques has failed.

Strong recommendation, low quality evidence.

Biliary stenting through ERCP or percutaneous transhepatic biliary drainage (PTBD) are established techniques described more than 40 years ago as alternatives to surgical biliodigestive anastomosis [31, 32].

Comparison of primary biliary stenting vs. surgical biliodigestive anastomosis for malignant biliary obstruction has been performed in three meta-analyses [33-35]; the two most recent ones included five identical RCTs (379 patients), of which four used ERCP and one the percutaneous approach to insert mostly plastic stents (SEMS were used in 15 patients only); two RCTs were added compared with the older meta-analysis [34, $35]$. In the two recent meta-analyses, procedure-related complications were more frequent with surgery vs. biliary stenting as well as 30 -day mortality ( $16.3 \%$ vs. $9.6 \%$ as stated by de Lima et al. [34]; incorrectly calculated by Glazer et al. [35]); shortterm success rates were similar with both techniques but recurrent biliary obstruction was less frequent after surgical bypass vs. stenting. Of note, the single RCT (30 patients) that used SEMSs found no difference between endoscopy and surgery in terms of late-onset complications and patient readmission [36]. Quality of life was assessed in two RCTs, one of these reported better results for endoscopic stenting [36] while the other one reported similar results for both drainage approaches [37]. The total duration of hospital stay, including patient readmissions, was shorter for biliary stenting vs. surgery in all of the five RCTs. Costs were analyzed in a single RCT: total costs (including readmissions) with endoscopic SEMS placement were approximately half those of surgery (4271 \pm 2411 vs. $8321 \pm$ 1821 USD) [38]. A similar difference has been reported in a large multicenter retrospective study that included 622 patients [39].

The comparison of biliary stenting through ERCP vs. PTBD was reported in the analysis of a national database and in two RCTs; all of these studies included both hilar and extrahepatic malignant biliary obstruction. The analysis of a U.S. database (9135 patients) found a lower adverse event rate $(8.6 \%$ vs. $12.3 \%)$, a shorter hospitalization, and lower total costs for ERCP vs. PTBD; mortality was not reported [40]. In that study, the lower rate of adverse events associated with endoscopic procedures was observed regardless of the volume of PTBD procedures performed in a center for pancreatic cancer. As mentioned above, endoscopic biliary stenting has been associated with longer patient survival and less frequent peritoneal/liver recurrence in the three retrospective series with long-term follow-up that compared this outcome for both approaches (total, 1213 patients) [22 - 24]. Finally, the two historical RCTs that compared ERCP vs. PTBD (75 and 54 patients) yielded contradictory results in terms of success rate and mortality $[41,42]$.

Endoscopic ultrasonography-guided biliary drainage (EUS$\mathrm{BD})$ has been more recently employed and is rapidly gaining acceptance: four meta-analyses (16-42 studies including 5-12 prospective ones; total, 528-1192 patients) reported that EUS-BD was clinically successful in $87 \%-94 \%$ of cases with adverse events reported in 16\% - 29\% [43-46]. EUS-BD has mostly been used in malignant conditions ( $87 \%$ of biliary obstructions in a meta-analysis that included 1186 patients) [43]. EUS-BD had a higher functional success rate in malignant vs. benign conditions in the single meta-analysis that analyzed that outcome, although technical success rates were similar [45].

This technique has mostly been used following failed ERCP (see section 5.4 for more details regarding its position in the treatment algorithm) although it has been used in pilot trials as a first-line option $[47,48]$.

\subsubsection{Type of stent}

\section{RECOMMENDATION}

ESGE recommends SEMS insertion for palliative drainage of malignant extrahepatic biliary obstruction.

Strong recommendation, high quality evidence.

Five meta-analyses have compared SEMSs with plastic stents for the endoscopic drainage of distal malignant biliary obstruction ( Table e2, available online) [49-53]. Compared with plastic stents, SEMSs are associated with a longer patient survival, a lower risk of stent dysfunction/cholangitis, and fewer reinterventions. Costs associated with palliation of malignant biliary obstruction with SEMSs vs. plastic stents have been compared in a meta-analysis (8 RCTs, 311 patients with hilar or extrahepatic malignant biliary obstruction) and in a more recent RCT (18 centers, 219 patients with extrahepatic malignant biliary obstruction) $[50,54]$. No significant differences in costs were reported in these studies and the more recent RCT showed total costs were also similar for plastic stents vs. SEMSs in patients with a short survival duration ( $\leq 3$ months) or those with metastatic disease [54]. A follow-up study (140 patients) of that RCT showed that health-related quality of life, both general and disease-specific, was better over time with SEMSs vs. plastic stents [55].

Seven meta-analyses have compared covered vs. uncovered SEMSs ( Table e3, available online) [56-62]; the covered SEMSs used in the original studies included partially covered SEMSs (PCSEMSS) and FCSEMSs. No differences in the propor- 
tions of patients with stent dysfunction, overall complications or patient survival were reported, except for stent dysfunction in two meta-analyses $[57,60]$. Covered SEMSs were associated with a lower risk of tumor ingrowth but a higher risk of stent migration, tumor overgrowth, and sludge formation. With respect to concerns about cholecystitis following covered SEMS placement [63], the four meta-analyses that reported this outcome found no increased risk of cholecystitis after insertion of covered vs. uncovered SEMS [58-61]. Of note, measures taken in some studies to prevent this complication have included placement of the stent covering below the level of the cystic duct implantation in patients with an intact gallbladder [64] and the use of covered SEMS with transmural drainage holes [65]. Finally, nitinol stents have replaced stainless steel stents as they perform better $[66,67]$.

Specific SEMS designs have been investigated:

- Antireflux covered SEMSs were compared with SEMSs devoid of an antireflux valve (an uncovered SEMS and a covered SEMS) in two RCTs $[68,69]$. Both RCTs reported a similar efficacy in decreasing bilirubin serum levels and a longer patency of antireflux vs. conventional SEMS. This is consistent with the finding that duodenal-biliary reflux is independently associated with biliary stone recurrence [70].

- Antimigration systems, including flared ends and anchoring flaps, have been tested with covered SEMSs [71, 72]. Anchoring flaps have yielded promising results in patients with benign strictures [71] but no study has compared identical stent designs with or without an antimigration system, precluding definitive conclusions. Stent models combining antireflux and antimigration systems have been tested in pilot trials [73].

- A radioactive stent, inserted percutaneously, provided longer patient survival than a similar, nonradioactive, stent in an RCT that included 23 patients with malignant biliary obstruction [74]. Another RCT (55 patients) that used a radioactive strand inserted between the stent and the biliary wall also reported prolonged patient survival [75].

- Paclitaxel-eluting stents provided no advantage compared with standard SEMSs in an RCT (72 patients) [76].

Only a few studies comparing different models of plastic stent have been published since 2011. A meta-analysis (five studies including three RCTs, 460 patients) found that double-layer plastic stents present a longer patency period, lower stent occlusion rates, and slightly more adverse events compared to conventional plastic stents [77]. No other specific designs have shown a clear benefit on clinical outcomes [78-81].

\subsubsection{Drainage of suspected malignant biliary obstruction}

\section{RECOMMENDATION}

ESGE recommends against the insertion of uncovered SEMS for the drainage of extrahepatic biliary obstruction of unconfirmed etiology.

Strong recommendation, low quality evidence.

In large series, $5 \%-10 \%$ of patients operated for pancreatic cancer prove to have benign disease at surgery [82]. Uncovered SEMSs are known to have poor long-term patency in benign disease [83]. These stents are difficult or impossible to remove and, although a new "stent-in-stent" technique has been successfully used to remove uncovered SEMSs mistakenly inserted in patients with a benign disease $[84,85]$, this technique is laborious and adverse events are frequent [86].

\subsubsection{Treatment of malignant bilioduodenal obstruction}

\section{RECOMMENDATION}

ESGE suggests endoscopic insertion of a biliary SEMS and an uncovered duodenal SEMS in patients with both biliary and duodenal malignant obstruction.

Weak recommendation, low quality evidence.

No study comparing endoscopic vs. surgical approach for combined biliary and duodenal drainage was found. Systematic reviews or meta-analyses have compared the endoscopic and surgical approaches for each condition separately:

- With respect to the bypass of a malignant obstruction of the duodenum/gastric outlet, seven meta-analyses were found

( $\triangleright$ Table e4, available online) [87 - 93]: they reported a high technical success rate for both approaches, with clinical success more frequently observed with SEMS vs. surgery in two meta-analyses. Five meta-analyses also reported a shorter delay before oral intake and a shorter duration of hospital stay with SEMS vs. surgery. Overall morbidity was similar for both approaches except in one meta-analysis that reported a lower morbidity with SEMS vs. surgery [89]. Among adverse events, those considered as major were more frequent with SEMS in two meta-analyses [87, 90]. EUS-guided gastroenterostomy using lumen-apposing SEMS (LAMS) has recently been introduced: in two retrospective studies, it was found to provide results similar to surgery and enteral stenting except for a lower incidence of symptom recurrence and need for reintervention compared with enteral stenting [94, 95];

- With respect to the approach for biliary drainage, the recommendation made above to prefer biliary stenting over surgical bypass is even stronger in the setting of malignant duodenal obstruction, as life expectancy of patients who present both duodenal and biliary stricture is short: in a retrospective study (81 patients with bilioduodenal stenting), 
median survival was 73 days [96]; even in patients with a "good" prognosis identified by a higher World Health Organization (WHO) score, another study reported a median survival of 139 days [97]. Although the procedure may be technically difficult, success rates of $86 \%-100 \%$ have been reported by experts in a prospective study, with lower success rates reported in cases where the duodenal stricture involves the papilla [98]. The technique and sequence of biliary and duodenal stenting according to different clinical scenarios is detailed in the ESGE Technical Review [2]. In the case of failed duodenal or biliary stenting, other interventions (e. g., PTBD, EUS-BD restricted to research settings) should be considered $[99,100]$.

\section{Stent dysfunction}

The diagnosis of stent dysfunction has not been standardized; it is usually based on the combination of clinical criteria and liver function tests, complemented with transabdominal ultrasound in some cases. Ultrasound is useful to search for biliary ductal dilatation, liver metastases, and liver abscesses. Examples of definitions of stent dysfunction used in RCTs are a decline in bilirubin $<20 \%$ following stent insertion (failed biliary drainage), development of cholangitis, jaundice, or a flu-like syndrome, and cholestasis [101]. More recent RCTs have mostly used paraclinical tests, as in the study by Schmidt et al. who defined stent dysfunction as the presence of two of the three following criteria: (a) ultrasound showing new dilatation of intrahepatic or extrahepatic bile ducts; (b) bilirubin $\geq 2 \mathrm{mg} / \mathrm{dL}$ ( $34.2 \mu \mathrm{mol} / \mathrm{L})$ with an increase $\geq 1 \mathrm{mg} / \mathrm{dL}(17.1 \mu \mathrm{mol} / \mathrm{L})$ compared to the value after initial successful drainage, or elevation of alkaline phosphatases/gamma-glutamyl transferase to more than twice the upper limit of normal values with an increase of at least $30 \mathrm{U} / \mathrm{L}$; (c) signs of cholangitis (fever and leukocyte count $>10000 / \mu \mathrm{L}$ or C-reactive protein (CRP) $>20 \mathrm{mg} / \mathrm{dL}$ ) [102].

\section{RECOMMENDATION}

ESGE suggests that in a patient with a distal malignant biliary stricture and a nonfunctioning stent, a plastic stent should be replaced by a SEMS and, in the case of a SEMS, a plastic stent or a new SEMS should be inserted within the original SEMS.

Weak recommendation, moderate quality evidence.

A meta-analysis (7 retrospective studies, 314 patients) found no difference in stent reocclusion when plastic stents vs. SEMSs were used to treat occluded SEMSs in patients with a malignant biliary obstruction (relative risk $1.24,95 \% \mathrm{Cl} 0.92-1.67$ ) [103]. In a more recent RCT, 48 patients with a malignant biliary obstruction who developed stent dysfunction were randomized to insertion of a plastic stent, uncovered SEMS, or PCSEMS [54]. Of these, 11 patients (23\%) again developed stent dysfunction, 8 in the plastic stent group, 1 in the uncovered SEMS group, and 2 in the PCSEMS group, with mean functional durations of 170 days, 367 days, and 326 days, respec- tively (plastic stent vs. SEMS; $P=0.026$ ). No differences in overall costs were found between secondarily placed SEMSs or plastic stents. Another RCT (43 patients with a nonfunctioning uncovered SEMS in a malignant distal biliary obstruction) found no difference in time to stent occlusion between covered vs. uncovered SEMS (112 vs. 181 days, respectively; $P>0.05$ ) [104].

Radiofrequency ablation was compared with the insertion of a plastic stent in a retrospective study of 50 patients with a nonfunctioning SEMS in malignant distal or proximal biliary obstruction: although radiofrequency ablation failed in $44 \%$ of patients (a plastic stent was inserted), stent patency duration was longer in the radiofrequency ablation group vs. the control group [105].

Finally, apart from specific stent designs mentioned above, no significant advances for the prevention of biliary stent dysfunction have been made since 2002, when a Cochrane metaanalysis showed the absence of benefit from any systemic treatment [106].

\section{Periprocedural and technical aspects of biliary stenting}

\subsection{Prophylaxis of post-ERCP pancreatitis}

\section{RECOMMENDATION}

ESGE recommends, for prophylaxis of post-ERCP pancreatitis, routine administration of $100 \mathrm{mg}$ of diclofenac or indomethacin intrarectally immediately before or immediately after ERCP in every patient with no contraindication. Strong recommendation, moderate quality evidence.

ESGE recommendations about the prophylaxis of post-ERCP pancreatitis have been updated in a specific Guideline to which the reader is referred [107]. One of its main recommendations is to routinely administer $100 \mathrm{mg}$ of diclofenac or indomethacin intrarectally immediately before or immediately after ERCP. We cannot overemphasize this point: despite the continuing accumulation of high quality evidence supporting the efficacy of this simple measure [108] except in low risk patients [109112 ], and the safety and the low price of diclofenac and indomethacin, their routine use has not been adopted by the majority of endoscopists $[113,114]$.

\subsection{Antibiotic prophylaxis}

\section{RECOMMENDATION}

ESGE suggests administration of antibiotic prophylaxis before biliary stenting in selected patients (e.g., immunocompromised patients, expected incomplete biliary drainage).

Weak recommendation, moderate quality evidence. 
Post-ERCP biliary infection is a serious complication that is fatal in $8 \%-20 \%$ of cases and it is best prevented by complete biliary drainage $[115,116]$. A relatively old meta-analysis (5 RCTs, 1029 patients) found the risk of sepsis/cholangitis following ERCP was not significantly decreased by routine antibiotic prophylaxis (odds ratio [OR] 0.91, 95\% confidence interval [Cl] 0.39 -2.15) [117]. More recently, guidelines have recommended antibiotic prophylaxis in patients with expected incomplete drainage of biliary obstruction, followed by a full antibiotic course if adequate drainage is not achieved during the procedure, as well as in patients with liver transplantation [118]. The authors suggested that prophylactic antibiotics may also be of benefit to patients with severe neutropenia (absolute neutrophil count $<500$ cells/ $\mu \mathrm{L}$ ) and/or advanced hematologic malignancy.

Recent studies are summarized below:

- A nationwide prospective study (31 188 patients) found, after adjustment for confounders, a $26 \%$ risk reduction in postoperative adverse events when prophylactic antibiotics were used (OR 0.74, 95\%Cl 0.69-0.79) [119]; nevertheless, the absolute risk reduction in adverse events $(2.6 \%$ in unselected patients and $3.8 \%$ in patients with obstructive jaundice) was estimated to be insufficient by the authors to justify routine antibiotic prophylaxis in unselected patients;

- A prospective study (183 unselected patients) found similar incidences of cholangitis with vs. without antibiotic prophylaxis, and all patients who developed cholangitis had incomplete drainage [120];

- A retrospective series (605 unselected patients) found that the increase in the incidence of post-ERCP cholangitis after routine antibiotic prophylaxis had been abandoned (1.7\% vs. $2.0 \%$ was not statistically significant [121]. In that study, sclerosing cholangitis and incomplete biliary drainage were significant risk factors for postoperative cholangitis;

- Another retrospective study (84 procedures, mostly in patients with sclerosing cholangitis) suggested that addition of antibiotics and antifungal agents to the contrast medium was associated with a lower risk of post-ERCP infectious complications (OR $0.33,95 \% \mathrm{Cl} 0.11-0.98)$, in particular in patients with incomplete biliary drainage [122].

\subsection{Endoscopic biliary sphincterotomy}

\section{RECOMMENDATION}

ESGE suggests against routine endoscopic biliary sphincterotomy before the insertion of a single plastic or an uncovered/partially covered SEMS.

Weak recommendation, moderate quality evidence.

Two meta-analyses have compared biliary stenting with vs. without endoscopic biliary sphincterotomy (EBS) [123,124]. The first meta-analysis (3 RCTs, 338 patients) found that EBS was associated with a reduced risk of post-ERCP pancreatitis (OR $0.34,95 \% \mathrm{Cl} 0.12-0.93$ ) and an increased risk of bleeding (OR 9.70, 95\%Cl 1.21-77.75); no significant difference was re- ported in the success of stent insertion and the rate of stent migration (OR 2.31, 95\% Cl $0.70-7.63)$. The second meta-analysis (5 RCTs, 12 comparative observational studies; 2710 patients) confirmed a higher risk of bleeding with EBS (OR $8.89,95 \% \mathrm{Cl}$ $2.76-28.73$ ) but no difference in terms of post-ERCP pancreatitis, stent migration, or occlusion [124]. Subgroup analysis according to the indication for biliary stenting suggested a protective effect of EBS against post-ERCP pancreatitis in patients who had biliary stenting for bile leak $(P=0.03)$ and no difference if biliary stenting was indicated for biliary obstruction. A subgroup analysis of the 6 studies (607 patients) in which SEMS were used found no difference in the incidence of postERCP pancreatitis in patients who had EBS or not. With respect to FCSEMS, a hypothetical concern has been raised that their coverage could obstruct the pancreatic outflow, leading to a high incidence of post-ERCP pancreatitis [125].

\subsection{Failed biliary stenting}

\subsubsection{Repeat attempts at ERCP}

ERCP initially fails in $10 \%-20 \%$ of patients because of difficult anatomy/inability to cannulate the papilla and to pass a guidewire across the stricture [126]. In such instances, the indication for repeating biliary intervention should be carefully reconsidered: in 7 studies of failed ERCP, ERCP was not repeated in 152 of 517 patients (29\%) [127 - 133]; reasons stated for this choice mostly included poor patient condition, futility, or replacement by another procedure such as endoscopic ultrasonographyguided sampling. In 9 studies that analyzed the role of repeat attempt at ERCP ( $\triangleright$ Table e5, available online), repeat ERCP was successful in 442 of 537 patients (82\%). Of note, the three studies that analyzed the timing of repeat ERCP found that ERCP was more frequently successful if it was repeated at least 2 days [129, 131] or 4 days [127] after the first attempt. A suggested explanation includes better visualization of the opening of the bile duct because of decreased edema or disappearance of submucosal injection. Factors that may favor success at repeat ERCP also include better patient sedation and team preparation, availability of ancillary material (e.g., specialized guidewires), and referral to another endoscopist in the same institution or in a high volume center. The morbidity associated with the first and subsequent ERCPs was similar in the studies that reported this outcome.

The reader is referred to the recent ESGE Guideline about the techniques of papillary cannulation and EBS at ERCP that includes an evidence-based algorithm for difficult biliary cannulation [134]. Of note, in patients with complex post-surgical anatomy including Billroth II gastrectomy, ESGE suggests referral to a specialized center.

\subsubsection{Role of EUS-BD}

More recently, the role of EUS-BD after failed biliary stenting at ERCP has been assessed in the literature:

- A meta-analysis that compared PTBD vs. EUS-BD (3 RCTs and 3 retrospective studies; total, 312 patients) found that clinical success was similar with both techniques (OR 1.48, 95\% CI $0.46-4.79$ ) but with fewer adverse events in the EUS-BD 
group (OR 0.34, 95\% Cl $0.20-0.59$ ); severe adverse events accounted for this difference [135]. The reintervention rates and costs were also lower with EUS-BD. Broadly similar findings were reported in a more recent retrospective study [136];

- An RCT (32 patients with a malignant distal biliary obstruction) found that, compared with surgical hepaticojejunostomy, EUS-BD presented a lower clinical success rate and a higher complication rate but differences were nonsignificant (71\% vs. $93 \%$ and $21 \%$ vs. $13 \%$, respectively) [137].

The concern has been expressed that EUS-BD might be used as a substitute for poor ERCP technique as the analysis of $>1600$ ERCPs in two tertiary referral centers has shown that EUS-BD was required in only $0.6 \%$ and $3.3 \%$ of ERCPs $[138,139]$. This aspect should not be disregarded by endoscopists with more experience in EUS-guided intervention than in ERCP.

With respect to the learning curve, a prospective study of 174 attempts at EUS-BD by a single endoscopist experienced in both EUS and ERCP suggested that 33 cases were required for learning EUS-guided hepaticogastrostomy as procedure duration decreased and adverse events tended to be less frequent $(36.4 \%$ and $20.8 \%, P=0.12)$ with practice [140].

Two meta-analyses compared the extrahepatic and intrahepatic routes for EUS-BD in subgroup analyses that included 8 and 10 studies $[43,45]$ : technical and functional success rates were similar with both routes in both studies and, in a single study, adverse events were less frequent with the extrahepatic vs. intrahepatic route ( $\mathrm{OR} 0.40 ; 95 \% \mathrm{Cl} 0.18-0.87 ; P=0.022$ ) [43]. In the particular situation of patients requiring EUS-BD and duodenal stenting, a retrospective study (39 patients) suggested that EUS-guided hepaticogastrostomy could provide longer biliary stent patency than EUS-guided choledochoduodenostomy [141].

With respect to stent choice, SEMSs are more frequently used than plastic stents ( 525 patients and 58 patients, respectively, in the meta-analysis by Wang et al. [45]); both types of stents provided similar technical and functional success rates but adverse events were more frequent with plastic stents vs. SEMSs (31\% vs. 18\%) [45]. Similar results were reported in an RCT that included 60 patients with EUS-guided choledochoduodenal stenting: SEMSs and plastic stents provided similar success rates but adverse events were more frequent with plastic stents (23\% vs. $13 \%$ ) and costs were lower with SEMSs [142]. Of note, fully or partially covered models of standard biliary SEMSs are usually selected for transmural biliary drainage to prevent bile leakage but dedicated SEMSs with a covering and antimigration flaps on one half of the SEMS have recently been tested $[143,144]$, with some models providing promising results [145-147]. Another promising device is a LAMS: in a multicenter retrospective study (57 patients with failed ERCP), LAMSs provided clinical success in $95 \%$ of patients with adverse events reported in $7 \%$. After a mean follow-up of 5 months, stent migration occurred in one patient (2\%) [147].

\section{Particular cases}

\subsection{Malignant hilar strictures}

6.1.1. Tumor assessment and patient referral

RECOMMENDATION

ESGE suggests assessing the resectability of malignant hilar strictures in the absence of biliary stents.

Weak recommendation, low quality evidence.

A meta-analysis (16 studies, 651 patients) found that $C T$, magnetic resonance imaging (MRI) and positron emission tomography (PET)/CT present similar accuracies for assessing resectability of hilar cholangiocarcinoma (CT, 71\%-95\%; MRI, $84 \%-93 \%$; PET/CT, 75\%-91\%) [148,149]. The authors acknowledged that imaging techniques are often combined as each technique may provide higher accuracy for a specific item (e.g., vascular invasion for CT, lymph node metastasis for $\mathrm{PET} / \mathrm{CT}$ ). The two studies (not included in the meta-analysis) that compared MRI and CT in identical patients with hilar cholangiocarcinoma (total, 36 patients) found that both techniques had similar accuracies for the evaluation of bile duct involvement $[150,151]$. Patients with biliary stents were excluded from these studies as from others because the staging accuracy of both modalities diminishes after biliary stent placement as a result of ductal decompression and imaging artifacts [152]. Measurement of liver volumes by CT and MRI is similarly effective $[153,154]$. Experience with EUS staging of hilar malignancy remains very limited.

\section{RECOMMENDATION}

ESGE recommends performing drainage of malignant hilar strictures in high volume centers with a multidisciplinary hepatobiliary team.

Strong recommendation, moderate quality evidence.

A meta-analysis (13 studies, 59437 ERCPs) showed that ERCP success is more frequent when it is performed by high volume vs. low volume endoscopists (OR 1.6, 95\% CI 1.2-2.1) and in high volume vs. low volume hospitals (OR 2.0, 95\% Cl 1.62.5), while adverse events are less frequent when ERCP is performed by high volume endoscopists [155]. As endoscopic stenting in malignant hilar strictures (MHSs) is an advanced procedure with a relatively high risk of failure, and survival is severely hampered after failed drainage $[156,157]$, the endoscopist's experience is even more important for MHSs than for distal malignant biliary strictures, as is the prompt availability of PTBD. Nevertheless, many patients with MHS are admitted to referral centers with a biliary stent already in place [158]. 


\subsubsection{Preoperative drainage of malignant hilar strictures}

\section{RECOMMENDATION}

ESGE suggests against routine preoperative biliary drainage in patients with malignant hilar obstruction. The indication and route for preoperative biliary drainage should be decided by a multidisciplinary team based on patient characteristics and institutional experience.

Weak recommendation, low quality evidence.

Two systematic reviews ( 11 studies, 711 patients and 9 studies, 892 patients) reported that preoperative biliary drainage of hilar cholangiocarcinoma was associated with a higher postoperative morbidity rate, in particular because of infections, and no significant difference in postoperative mortality [159, 160]. However, many authors have suggested that in specific situations (e. g., cholangitis, predicted future liver remnant volume of $\leq 30 \%$ following surgery), preoperative drainage could be indicated [161]. These situations have been associated with a high risk of postoperative liver failure and may thus benefit from portal vein embolization and drainage limited to the future liver remnant segments [162].

With respect to the choice between the endoscopic and percutaneous approaches for preoperative biliary drainage, two meta-analyses ( 4 retrospective studies, 433 patients, and 3 retrospective studies, 265 patients) reported a similar [163] or higher [164] procedure-related morbidity for ERCP vs. PTBD. On the other hand, a large, more recent, retrospective study (280 patients) found that major postoperative morbidity was more frequent after PTBD vs. ERCP for drainage of MHS [165]. A single meta-analysis analyzed long-term survival; it was shorter following PTBD vs. ERCP (30\% vs. $46 \%$ at 5 years) [163]. A similarly shorter patient survival following PTBD vs. ERCP was reported in three large retrospective studies (793 patients) not included in the meta-analyses [166-168]. Peritoneal metastasis was more frequent following PTBD vs. ERCP; it may be associated with the duration of PTBD (60 days or more) and the presence of multiple PTBD catheters [169]. A similar association between preoperative PTBD and shorter survival has not been found in a Western bicentric study (245 patients) with a different use of PTBD catheters [170].

If endoscopic preoperative drainage of MHS is performed, plastic stents or nasobiliary drains are preferred [171]; although less comfortable for the patient, nasobiliary drains are preferred in particular by Japanese authors because of the lower incidence of cholangitis due to tube occlusion [172]. The use of SEMSs for preoperative drainage of MHS is discouraged because of the paucity of the literature [173] and the risk of precluding curative surgery.

\subsubsection{Palliative drainage of malignant hilar strictures}

\section{RECOMMENDATION}

ESGE suggests palliative drainage of malignant hilar strictures by means of ERCP for Bismuth types I and II, and PTBD or a combination of PTBD and ERCP for Bismuth types III and IV, to be modulated according to local expertise.

Weak recommendation, low quality evidence.

\section{RECOMMENDATION}

ESGE suggests, for palliative endoscopic drainage of Bismuth types II - IV strictures, drainage of $\geq 50 \%$ of the liver volume and avoidance of the opacification of biliary ducts that will not be drained.

Weak recommendation, low quality evidence.

\section{RECOMMENDATION}

ESGE recommends uncovered SEMSs for palliative drainage of malignant hilar obstruction.

Strong recommendation, moderate quality evidence.

A meta-analysis (7 retrospective studies and 2 RCTs, 546 patients) found that PTBD was more frequently successful than ERCP for palliation of Bismuth types III and IV MHS (OR 2.53, $95 \% \mathrm{Cl} 1.57-4.08$ ) [174]. Overall adverse events and 30-day mortality were similar for both approaches. Bismuth types I and II MHS were not included in the meta-analysis because ERCP was believed to represent the optimal approach for palliative drainage of such strictures. Of note, drainage of Bismuth type I MHS is technically similar to that of extrahepatic biliary strictures. The value of this meta-analysis is limited by the fact that most data were retrospective, including three noncomparative studies. With respect to quality of life, it improves with both approaches $[175,176]$ but an RCT (54 patients) suggested that some health parameters improve more with PTBD vs. ERCP [177].

An RCT (54 patients with a potentially resectable hilar cholangiocarcinoma) reported a higher perioperative mortality with PTBD vs. ERCP [178]. In a retrospective study (110 patients with a Bismuth type III and IV MHS), failed endoscopic biliary drainage was associated with an acute angle between the common bile duct (CBD) and the left hepatic duct at pre-drainage imaging; this could help to decide on the best individual approach in centers where ERCP is used for draining Bismuth types III and IV MHS [179].

The minimal proportion of liver volume, excluding tumor volume, that should be drained was analyzed in a retrospective study (78 patients): serum bilirubin dropped by $\geq 50 \%$ if $33 \%$ or $50 \%$ of liver volume was drained in patients with either normal liver function/compensated cirrhosis or decompensated cirrhosis, respectively [180]. These results are in line with prior studies $[181,182]$; one of these also showed a lower incidence of 
cholangitis and longer patient survival with endoscopic drainage of $>50 \%$ of the liver volume [182].

Unilateral and bilateral drainage of MHS have been compared in three meta-analyses $[53,183,184]$. Two of these ( 7 studies, 634 patients; 4 studies, 562 patients) found a significant difference only in the success of stent insertion (higher with unilateral stenting) while other outcomes were similar, including therapeutic success, cumulative stent patency, complications, and survival. The third meta-analysis (28 mostly noncomparative studies, 2132 patients) reported the following: (i) for plastic stents, no difference for any outcome, including success of stent insertion, overall complications, and 30-day mortality; (ii) for SEMSs, a higher technical success rate, more overall adverse events, less decrease in serum bilirubin, and similar 30day mortality with unilateral vs. bilateral stenting [183]. In these meta-analyses, the only study that randomized patients to unilateral vs. bilateral stenting used plastic stents, which are no longer standard of care. More recently, a multicenter RCT (133 patients with MHS of Bismuth type $\geq$ II treated with SEMSs) addressed most biases of the studies included in the abovementioned meta-analyses, namely the inclusion of patients with Bismuth type I MHS that can be fully drained with a single stent, the use of both SEMS and plastic stent, and the inclusion of patients undergoing palliative drainage as well as PBD: bilateral drainage resulted in fewer reinterventions and a more durable stent patency (median 252 vs. 139 days) [185].

Contrast-free deep cannulation into the ductal systems to be drained has been proposed to prevent post-ERCP cholangitis, a frequent complication after injection of obstructed ducts that are not subsequently drained [186-188]. In this technique, pre-ERCP imaging is used as a road map to insert a guidewire into the desired obstructed duct(s) while avoiding injection of contrast medium upstream from the stricture; once the stricture has been crossed bile is aspirated and contrast medium is injected before stent insertion. Various contrast media have been used: air, carbon dioxide (CO2) (to decrease the risk of gas embolism), or iodine contrast. Some authors have proposed no use of contrast at all, delineating the stricture with the waist of the SEMS [189]. Two RCTs (85 patients) [190,191] and two retrospective studies (235 patients) [192, 193] found that post-ERCP cholangitis was less frequent if air/CO2 rather than iodine contrast was used for cholangiography in patients with Bismuth type $\geq$ II hilar stricture. Three uncontrolled studies have reported a low $(0-6 \%)$ rate of post-ERCP cholangitis using iodine contrast for injection upstream from the MHS [194, 195] or using no contrast medium injection [189].

Plastic stents and SEMSs have been compared in three metaanalyses; one of these included three RCTs (188 patients) [50] and the two others included, in addition to these, one prospective and two retrospective studies (total, 800 patients) [51, 53]. One meta-analysis of RCTs showed better results with SEMSs in terms of stent dysfunction (risk difference $-0.17,95 \% \mathrm{Cl}-0.28$ to -0.06 ), reintervention (risk difference $-0.30,95 \% \mathrm{Cl}-0.54$ to -0.06 ), and mean survival (159 vs. 99 days) [50], while the other meta-analyses reported that SEMSs were also associated with less therapeutic failure (OR $0.28,95 \% \mathrm{Cl} 0.13-0.63$ ) [51, 53]. SEMSs are cost-effective according to one RCT [196] and a decision analytic model [197], but not according to a retrospective study [198]. Uncovered SEMS were used in all studies except a recent retrospective series (30 patients) that reported encouraging results with a 6-mm diameter FCSEMS, although liver abscesses were reported in $7 \%$ of patients because of a stent crossing a duct bifurcation; in this pilot study removable FCSEMS were used to prevent stent ingrowth and to facilitate reintervention [199]. Of note, if a decision for palliation has not been taken, plastic stents are recommended because removal of uncovered SEMSs is usually not possible [200].

The "side-by-side" and "stent-in-stent" positioning of multiple SEMSs have been found equivalent in a meta-analysis (4 studies, 158 patients) with respect to the rates of successful stent placement, successful drainage, early and late complications, and stent occlusions [201]. The choice of the technique thus seems to be at the discretion of the endoscopist, with the "side-by-side" and "stent-in-stent" techniques more frequently used in Western and Asian countries, respectively. The insertion of side-by-side SEMSs has become easier with the availability of small-diameter delivery catheters that can be passed simultaneously in a standard therapeutic channel duodenoscope and permit simultaneous SEMS deployment [202]. Different precautions should be taken with each technique (e.g., with the "side-by-side" technique, the SEMSs should cross the papilla or their lower extremities should be positioned at the same level in the CBD to facilitate further stent access).

Dysfunction of plastic stents is treated by stent removal, cleaning of ductal debris, and SEMS insertion, unless the diagnosis is not yet clear or patient life expectancy is very limited. In the case of SEMS occlusion, cleaning of ductal debris with a balloon is suggested, followed by cholangiographic assessment of the degree of tissue ingrowth/overgrowth and subsequent insertion of an inner plastic stent or SEMS [203]; a retrospective study (52 patients) reported a longer patency (131 days vs. 47 days) with SEMSs vs. plastic stents [204]. Radiofrequency ablation might be an alternative option although data are sparse and comparison with insertion of a plastic stent has been reported in only one retrospective study [205].

\subsection{Benign strictures}

\section{RECOMMENDATION}

ESGE recommends temporary insertion of multiple plastic stents or of a fully covered SEMS for treatment of benign biliary strictures.

Strong recommendation, moderate quality evidence. The choice between the two strategies depends on the etiology of the stricture, its location, the CBD diameter, and endoscopist experience.

Endoscopy has become the preferred option for treating benign biliary stricture (BBS) [206-209]. Endoscopic treatment is performed mostly for BBSs related to liver transplantation or chronic pancreatitis (one third of cases each) and, less frequently, to other causes (e.g., post-cholecystectomy and 
post-sphincterotomy strictures); about $85 \%$ of BBSs are located at the level of the CBD [210].

Treatment of BBSs with a single plastic stent or uncovered SEMS has long been abandoned because of poor long-term results [211,212]. A meta-analysis (four RCTs, 213 patients) found that temporary insertion of either MPS or of a covered SEMS for the treatment of BBSs of various origins provided similar results (ORs [95\%Cls] for stricture resolution, recurrence, and adverse events, respectively: 1.07 [0.97-1.18], 0.88 $0.48-1.63]$, and 1.16 [0.71-1.88]) [213]. Fewer ERCPs were required with covered SEMSs (mean difference $-1.71,95 \% \mathrm{Cl}$ -2.34 to -1.09$)$. The largest RCT included in the meta-analysis (112 patients) did not include patients with a BBS located within $2 \mathrm{~cm}$ from the hepatic confluence, a CBD diameter $<6 \mathrm{~mm}$, or an intact gallbladder in whom the cystic duct would have been overlapped by a FCSEMS. The two RCTs (20 patients) that analyzed the costs of each treatment found it was approximately half with the use of covered SEMSs [214,215].

Stricture recurrence after endoscopic treatment is usually managed with repeat endoscopic stent placement [216, 217].

\section{RECOMMENDATION}

ESGE suggests, for multiple plastic stenting, insertion of the maximum number of stents possible every 3-4 months for a total duration of 12 months and, for treatment with FCSEMS, insertion of an $8-10$-mm diameter FCSEMS for a dwell stenting period of 6 months.

Weak recommendation, low quality evidence.

With plastic stents, the current strategy consists in inserting an increasing number of plastic stents every 3-4 months even though some authors have proposed different intervals for stent exchange [218-220]. The criteria used for treatment termination have included complete morphologic disappearance of the stricture, passage of a balloon biliary catheter, or a fixed 12 -month stenting duration [218, 221, 222]. In most series the stenting duration has been approximately 12 months; a retrospective study (156 patients) reported that stricture recurrence was independently associated with a stricture diameter of less than $75 \%$ compared to that of the surrounding CBD at the end of treatment while the association with stenting duration was significant in univariate analysis only [223].

With respect to SEMSs, partially covered SEMS have been replaced by FCSEMS in this indication because tissue hyperplasia can develop through the bare ends, complicating SEMS removal or causing biliary stricture [224-227]. Stent migration is the most frequent adverse event related to FCSEMS ( $9 \%$ in a metaanalysis of 37 studies, 1677 patients) [228] and it is associated with a $80 \%$ decrease in the odds of stricture resolution [229, 230]. Stent designs aimed at preventing stent migration include flared ends (Wallflex), anchoring fins (Viabil, Hanaro) and a short stent length allowing complete intrabiliary stent deployment (Taewoong) [231]. Anchoring fins were more effective than flared ends to reduce stent migration in a retrospective study (134 patients) but some models have been asso- ciated with traumatic biliary mucosal lesions and possibly the development of de novo biliary strictures, including after stent removal ( $8.1 \%$ of 37 patients in a retrospective study) [232, 233].

The ideal duration of FCSEMS dwell is unknown; in a metaanalysis (37 studies, 1677 patients), the median stenting duration was 4.4 months [228]; another meta-analysis (22 studies, 1298 patients) found a lower stricture recurrence with 6 vs. 3 months or less of stent therapy [213].

With respect to the need for EBS before FCSEMS insertion for this indication, it has been performed in most series [227]; a retrospective series reported a very high incidence of postERCP pancreatitis (50.0\%, including one fatal case) that decreased to $12.5 \%$ once EBS was routinely performed [125].

\subsubsection{Benign biliary strictures related to chronic pancreatitis}

\section{RECOMMENDATION}

ESGE suggests the temporary insertion of multiple plastic stents or of an FCSEMS for treating benign biliary strictures related to chronic pancreatitis.

Weak recommendation, moderate quality evidence.

An RCT (60 patients with chronic pancreatitis) found that MPS and covered SEMSs provided similar success rates 2 years after stent removal ( $88.0 \%$ vs. $90.9 \%$, respectively) with similar treatment-related morbidity $(23.3 \%$ vs. $28.6 \%$, respectively) [234]. The stenting duration was 6 months in both groups and the removal of covered SEMS was problematic in 4 of 28 patients $(14.3 \%)$ because of stent fracture $(n=3)$ and embedment $(n=1)$, mostly at the beginning of the authors' experience when partially covered SEMS were used (FCSEMS were used once they became available).

A systematic review concluded that covered SEMSs provided better results than MPS in chronic pancreatitis-related biliary strictures, but it included noncomparative studies only and single plastic stents were used in a significant proportion of patients in all of the three studies labeled as MPS (e.g., $33 \%$ in the study by Eickhoff et al.) [235, 236].

Patient compliance may be particularly problematic in patients with alcoholic chronic pancreatitis, and biliary bypass surgery (e.g., hepaticojejunostomy) remains a valid option for noncompliant patients or if the stricture does not respond to biliary stenting [237]. 


\subsubsection{Benign anastomotic biliary strictures following liver transplantation}

\section{RECOMMENDATION}

ESGE suggests temporary insertion of multiple plastic stents for the treatment of benign anastomotic biliary strictures following orthotopic liver transplantation pending further evidence about FCSEMS.

Weak recommendation, moderate quality evidence

Anastomotic biliary strictures (ABSs) are more frequent following living donor liver transplantation (LDLT) vs. deceased donor liver transplantation (DDLT); LDLT-related ABSs are also more difficult to treat, with risks of technical treatment failure and of stricture recurrence being $23 \%$ and $25 \%$ higher, respectively [238]. Predictors of failed endoscopic treatment of LDLTrelated $A B S s$ include higher liver transplantation recipient age, longer operation duration, pouched morphology of the ABS, multiple ductal anastomosis, and persistent bile leak [239241]. The treatment of LDLT-related ABSs is performed in highly specialized centers and its modalities are not considered in the current Guideline.

Three RCTs (20, 58, and 64 DDLT recipients) compared covered SEMS vs. MPS for the treatment of ABSs: two RCTs reported no difference between groups except for a lower number of ERCPs with FCSEMSs vs. MPS [214,242], while the largest RCT reported higher stricture recurrence and adverse event rates with covered SEMSs vs. MPS (32.0\% vs. $0 \%$ and $23.3 \%$ vs. $6.4 \%$, respectively) (the authors did not mention whether SEMSs were fully or partially covered) [215]. These RCTs were not included in a review of 13 noncomparative studies (601 patients) which reported that, in patients with an ABS following DDLT, the stricture resolution rates were higher with MPS vs. FCSEMSs $(87.2 \%$ vs. $61.8 \%$ ) while recurrence and adverse event rates were similar [243].

\subsubsection{Post-cholecystectomy benign biliary strictures}

\section{RECOMMENDATION}

ESGE suggests temporary insertion of multiple plastic stents for the treatment of benign biliary strictures complicating cholecystectomy; a FCSEMS can be an alternative for strictures located $>2 \mathrm{~cm}$ from the main hepatic confluence.

Weak recommendation, moderate quality evidence.

A single RCT (31 patients) compared MPS (average 4.8 stents) vs. PCSEMSs ( $8-10-\mathrm{mm}$ diameter) in patients with BBSs mostly related to cholecystectomy [244]. Adverse event rates were similar with both types of stent and, based on MRI, long-term success was stated to be better with PCSEMSs $(81.7 \%$ vs. $71.9 \%$ ). However, the significance is doubtful because of the low number of patients and the uncommon, undetailed, measure of success. In the largest RCT that compared MPS vs.
FCSEMSs, only 4 of 112 patients (3.6\%) had postoperative injuries that were not related to liver transplantation as many postcholecystectomy strictures occur too close to the hepatic confluence to accommodate SEMS [245].

On the other hand, the study with the longest follow-up available (>13 years) used MPS and reported no stricture recurrence in $88.6 \%$ of 35 patients followed retrospectively [216]. Similar results were reported by the same group of authors in a cohort extended to 164 patients with a follow-up of 7 years; notably half of the patients had a post-cholecystectomy BBS that involved the main hepatic confluence, a feature that has become more frequent with the advent of laparoscopic cholecystectomy [246]. For BBSs located $>2 \mathrm{~cm}$ from the main hepatic confluence FCSEMS can present the advantage of fewer ERCPs and shorter treatment.

\subsection{Biliary leaks}

\section{RECOMMENDATION}

ESGE recommends endoscopic placement of plastic stent(s) to treat bile duct leaks that are not due to transection of the common bile duct or common hepatic duct.

Strong recommendation, moderate quality evidence. SEMS may be valuable in the case of refractory bile leak.

ESGE does not recommend a primary endoscopic approach to drain bilomas.

Strong recommendation, low quality evidence.

Various forms of endoscopic treatment, i. e., biliary stenting, EBS, and nasobiliary drainage, are highly effective to treat biliary leaks except in the case of transection of a large duct; of note the time lapse between biliary injury and endoscopic treatment does not seem to affect important outcomes [247].

Some of the available treatment options were compared in three RCTs. One of these (27 patients) found that fistulas tended to close more rapidly with biliary stenting vs. EBS [248]. Another RCT (52 patients) found no difference in terms of efficacy between the placement of a plastic stent alone or combined with EBS [249]. With respect to the stent diameter, an RCT (63 patients) reported similar proportions of patients with leak closure using 7-Fr vs. 10-Fr plastic stents [250]. The duration of stenting has not been specifically investigated; it is $4-8$ weeks in many studies.

In patients with a post-cholecystectomy bile leak that persisted following the insertion of a single plastic stent, FCSEMSs were superior to MPS in a comparative nonrandomized study (40 patients) [251].

EBS alone is attractive because it does not imply repeat endoscopy but this advantage should be balanced against potential short-term and long-term complications. The latter consist of cholangitis and pancreatitis (OR 1.7 [95\% Cl 1.3-2.4] and $1.5[95 \% \mathrm{Cl} 1.0-2.4]$, respectively, compared with adequate controls at a median follow-up of 15 years) [252]. 
Case series suggest that temporary transpapillary biliary drainage may also be effective to treat bile leaks due to liver resections [253, 254].

Bilomas are a frequent complication of biliary leaks that may require drainage; this is traditionally performed percutaneously but several case series have reported its feasibility under EUS guidance [255]. A retrospective series (27 patients with liver abscess) has reported a trend for better results as well as a significantly shorter hospital stay for EUS-guided vs. percutaneous drainage [256]. Nevertheless, more data are needed before this approach may be recommended in specific situations [257, 258].

\subsection{Failed extraction of biliary stones}

\section{RECOMMENDATION}

ESGE suggests endoscopic placement of a temporary biliary plastic stent in patients with irretrievable biliary stones.

Weak recommendation, moderate quality evidence.

If CBD stones cannot be removed during ERCP because of patient condition or technical factors, a biliary stent may be inserted to both drain the bile ducts and facilitate delayed stone extraction, as stone size will decrease by a mean of $50 \%$ in $2-6$ months [259]. An RCT in 86 frail patients has shown that shortterm complications tend to be less frequent with this strategy compared with attempted CBD stone removal [260].

Plastic stents have been used in most studies and no comparison between the different types and diameters is available. A meta-analysis (6 studies, 885 patients) showed that the risk of cholangitis is highly increased with permanent stenting vs. elective stent exchange (OR 5.32, 95\%Cl 2.23-12.68) [259]. Therefore, stenting for biliary stones should be considered a temporary measure until bile duct clearance is achieved. The ideal timeframe for stent exchange has not been defined. An RCT (78 patients) has reported a lower incidence of cholangitis following the insertion of a 10-Fr stent if the stent was exchanged every 3 months vs. on demand [261]. These findings are in line with a retrospective study (64 patients) that reported a higher stent patency rate at 3 months with two plastic stents vs. one [262].

FCSEMSs have been used in six retrospective series (total 160 patients) [263] and stones were successfully removed in 127 of 144 attempted cases (88\%), most often with a simple balloon sweep. Adverse events were noted in 29 cases (18\%) and the cost-effectiveness has not been compared with that of plastic stents.

\section{Stent registry}

\section{RECOMMENDATION}

ESGE recommends maintaining a registry of patients with biliary stents, in particular for patients with a benign biliary disease, and to recall them for stent removal/exchange.

Strong recommendation, low quality evidence.

Measures should be taken to avoid leaving biliary stents in place for too long, as "forgotten" stents may be extremely difficult to remove (requiring surgery in $76 \%$ of 21 patients in a retrospective series) and caused death in $6.7 \%$ of patients in a prospective series [264]. Maintaining a registry of stents inserted with the purpose of recalling patients due for stent exchange or removal allowed a decrease in the incidence of stent-related sepsis in an Australian endoscopy unit [265]. An RCT (48 patients) showed that mobile phone reminder messages may increase patient adherence to stent removal/exchange [266]. Of course, patient compliance with repeat interventions should be ensured prior to treatment.

\section{Disclaimer}

The legal disclaimer for ESGE Guidelines [3] applies to the current Guideline.

\section{Acknowledgments}

The authors gratefully acknowledge Dr. Lars Aabakken, GI Endoscopy, OUS-Rikshospitalet University Hospital, Oslo, Norway, Dr. Todd H. Baron, Division of Gastroenterology and Hepatology, University of North Carolina, Chapel Hill, North Carolina, USA, Dr Gregory A. Cote, Division of Gastroenterology and Hepatology, Medical University of South Carolina, Charleston, South Carolina, USA, and Dr. Thierry Ponchon, Hepatogastroenterology Department, Hôpital Edouard Herriot, Hospices Civils de Lyon, Lyon, France, for their critical review of the Guideline.

\section{Competing interests}

G. Costamagna has provided research support to Cook Medical and Taewoong; his department has received research support from Boston Scientific. J. Devière's department has received research support for institutional review board-approved studies, from Olympus (ongoing), Boston Scientific (ongoing), and Cook Medical (from 2015 to 2016). F. Prat has provided consultancy to Olympus (2016 to 2018 , continuing) and Boston Scientific (2015 to 2018, continuing). P.D. Siersema has provided research support to Ella-CS (from June 2016 to present). J. van Hooft has received lecture fees from Medtronic (from 2014 to 2015) and consultancy fees from Boston Scientific (from 2014 to 2016); her department has received research grants from Cook Medical (from 2014 to 2017) and Abbott (from 2014 to 2017). G. Vanbiervliet has provided consultancy to Boston Scientific (from 2016 to present). D. Blero, J.-M. Dumonceau, J. García-Cano, T. Gyökeres, C. Hassan, B. Mangiavillano, I.S.Papanikolaou, A. Schmidt, and A. Tringali have no competing interests. 


\section{References}

[1] Dumonceau JM, Tringali A, Blero D et al. Biliary stenting: indications, choice of stents and results: European Society of Gastrointestinal Endoscopy (ESGE) clinical guideline. Endoscopy 2012; 44: 277-298

[2] Dumonceau JM, Heresbach D, Deviere J et al. Biliary stents: models and methods for endoscopic stenting. Endoscopy 2011; 43: 617-626

[3] Dumonceau JM, Hassan C, Riphaus A et al. European Society of Gastrointestinal Endoscopy (ESGE) Guideline development policy. Endoscopy 2012; 44: 626-629

[4] Guyatt G, Oxman AD, Akl EA et al. GRADE guidelines: 1. Introduction - GRADE evidence profiles and summary of findings tables. J Clin Epidemiol 2011; 64: 383 -394

[5] Jinkins LJ, Parmar AD, Han Y et al. Current trends in preoperative biliary stenting in patients with pancreatic cancer. Surgery 2013; 154 : $179-189$

[6] Cooper AB, Parmar AD, Riall TS et al. Does the use of neoadjuvant therapy for pancreatic adenocarcinoma increase postoperative morbidity and mortality rates? J Gastrointest Surg 2015; 19: 80 - 86, discussion 86-87

[7] Cabral V, Zhou J. Preoperative biliary drainage for pancreatic head carcinoma: A systematic review and meta-analysis. Biomed Lett 2015; $1: 81-87$

[8] Chen Y, Ou G, Lian G et al. Effect of preoperative biliary drainage on complications following pancreatoduodenectomy: a meta-analysis. Medicine 2015; 94: e1199

[9] Qiu Y-D, Bai J-L, Xu F-G et al. Effect of preoperative biliary drainage on malignant obstructive jaundice: a meta-analysis. World J Gastroenterol 2011; 17: 391 - 396

[10] Sun C, Yan G, Li Z et al. A meta-analysis of the effect of preoperative biliary stenting on patients with obstructive jaundice. Medicine 2014; 93: e189

[11] Saleh MMA, Nørregaard P, Jørgensen HL et al. Preoperative endoscopic stent placement before pancreaticoduodenectomy: A meta-analysis of the effect on morbidity and mortality. Gastrointest Endosc 2002; 56: 529- 534

[12] Velanovich V, Kheibek T, Khan M. Relationship of postoperative complications from preoperative biliary stents after pancreaticoduodenectomy. A new cohort analysis and meta-analysis of modern studies. JOP 2009; 10: $24-29$

[13] Fang Y, Gurusamy KS, Wang Q et al. Meta-analysis of randomized clinical trials on safety and efficacy of biliary drainage before surgery for obstructive jaundice. Br J Surg 2013; 100: 1589-1596

[14] Sewnath ME, Karsten TM, Prins MH et al. A meta-analysis on the efficacy of preoperative biliary drainage for tumors causing obstructive jaundice. Ann Surg 2002; 236: $17-27$

[15] Scheufele F, Schorn S, Demir IE et al. Preoperative biliary stenting versus operation first in jaundiced patients due to malignant lesions in the pancreatic head: A meta-analysis of current literature. Surgery 2017; 161: $939-950$

[16] Moole H, Bechtold M, Puli SR. Efficacy of preoperative biliary drainage in malignant obstructive jaundice: a meta-analysis and systematic review. World J Surg Oncol 2016; 14: 182

[17] Barauskas G, Urbonas K, Smailyte G et al. Preoperative endoscopic biliary drainage may negatively impact survival following pancreatoduodenectomy for ampullary cancer. Dig Surg 2016; 33: 462 - 469

[18] Furukawa K, Shiba H, Shirai Y et al. Negative impact of preoperative endoscopic biliary drainage on prognosis of pancreatic ductal adenocarcinoma after pancreaticoduodenectomy. Anticancer Res 2015; 35 : $5079-5083$

[19] Sauvanet A, Boher JM, Paye F et al. Severe jaundice increases early severe morbidity and decreases long-term survival after pancreatico- duodenectomy for pancreatic adenocarcinoma. J Am Coll Surg 2015; 221: $380-389$

[20] van der Gaag NA, Rauws EA, van Eijck CH et al. Preoperative biliary drainage for cancer of the head of the pancreas. N Engl J Med 2010; 362: $129-137$

[21] Arkadopoulos N, Kyriazi MA, Papanikolaou IS et al. Preoperative biliary drainage of severely jaundiced patients increases morbidity of pancreaticoduodenectomy: results of a case-control study. World J Surg 2014; 38: 2967-2972

[22] Miura F, Sano K, Wada K et al. Prognostic impact of type of preoperative biliary drainage in patients with distal cholangiocarcinoma. Am J Surg 2017; 214: $256-261$

[23] Strom TJ, Klapman JB, Springett GM et al. Comparative long-term outcomes of upfront resected pancreatic cancer after preoperative biliary drainage. Surg Endosc 2015; 29: 3273 - 3281

[24] Uemura K, Murakami Y, Satoi S et al. Impact of preoperative biliary drainage on long-term survival in resected pancreatic ductal adenocarcinoma: a multicenter observational study. Ann Surg Oncol 2015; 22: (Suppl. 03): $1238-1246$

[25] Crippa S, Cirocchi R, Partelli S et al. Systematic review and metaanalysis of metal versus plastic stents for preoperative biliary drainage in resectable periampullary or pancreatic head tumors. Eur J Surg Oncol 2016; 42: $1278-1285$

[26] Song T], Lee JH, Lee SS et al. Metal versus plastic stents for drainage of malignant biliary obstruction before primary surgical resection. Gastrointest Endosc 2016; 84: 814-821

[27] Gardner TB, Spangler CC, Byanova KL et al. Cost-effectiveness and clinical efficacy of biliary stents in patients undergoing neoadjuvant therapy for pancreatic adenocarcinoma in a randomized controlled trial. Gastrointest Endosc 2016; 84: 460-466

[28] Adams MA, Anderson MA, Myles JD et al. Self-expanding metal stents (SEMS) provide superior outcomes compared to plastic stents for pancreatic cancer patients undergoing neoadjuvant therapy. | Gastrointest Oncol 2012; 3: 309-313

[29] Tsuboi T, Sasaki T, Serikawa M et al. Preoperative biliary drainage in cases of borderline resectable pancreatic cancer treated with neoadjuvant chemotherapy and surgery. Gastroenterol Res Pract 2016; 2016: 7968201

[30] Cavell LK, Allen P], Vinoya C et al. Biliary self-expandable metal stents do not adversely affect pancreaticoduodenectomy. Am J Gastroenterol 2013; 108: 1168-1173

[31] Pereiras RV, Rheingold OJ, Huston D et al. Relief of malignant obstructive jaundice by percutaneous insertion of a permanent prosthesis in the biliary tree. Ann Intern Med 1978; 89: 589-583

[32] Soehendra N, Reynders-Frederix V. Palliative bile duct drainage a new endoscopic method of introducing a transpapillary drain. Endoscopy 1980; 12: 8-11

[33] Taylor MC, McLeod RS, Langer B. Biliary stenting versus bypass surgery for the palliation of malignant distal bile duct obstruction: a meta-analysis. Liver Transpl 2000; 6: 302-308

[34] de Lima SLA, Bustamante FAC, de Moura EGH et al. Endoscopic palliative treatment versus surgical bypass in malignant low bile duct obstruction: A systematic review and meta-analysis. Int J Hepatobiliary Pancreat Dis 2015; 5: 35-46

[35] Glazer ES, Hornbrook MC, Krouse RS. A meta-analysis of randomized trials: immediate stent placement vs. surgical bypass in the palliative management of malignant biliary obstruction. J Pain Symptom Manage 2014; 47: $307-314$

[36] Artifon EL, Sakai P, Cunha JE et al. Surgery or endoscopy for palliation of biliary obstruction due to metastatic pancreatic cancer. Am J Gastroenterol 2006; 101: 2031-2037 
[37] Andersen JR, Sørensen SM, Kruse A et al. Randomised trial of endoscopic endoprosthesis versus operative bypass in malignant obstructive jaundice. Gut 1989; 30: 1132 - 1135

[38] Artifon ELA, Sakai P, Cunha JEM et al. Surgery or endoscopy for palliation of biliary obstruction due to metastatic pancreatic cancer. Am J Gastroenterol 2006; 101: $2031-2037$

[39] Bliss LA, Eskander MF, Kent TS et al. Early surgical bypass versus endoscopic stent placement in pancreatic cancer. HPB (Oxford) 2016; 18: $671-677$

[40] Inamdar S, Slattery E, Bhalla R et al. Comparison of adverse events for endoscopic vs percutaneous biliary drainage in the treatment of malignant biliary tract obstruction in an inpatient national cohort. JAMA Oncol 2016; 2: $112-117$

[41] Speer AG, Cotton PB, Russell RC et al. Randomised trial of endoscopic versus percutaneous stent insertion in malignant obstructive jaundice. Lancet 1987; 2: 57-62

[42] Piñol V, Castells A, Bordas JM et al. Percutaneous self-expanding metal stents versus endoscopic polyethylene endoprostheses for treating malignant biliary obstruction: randomized clinical trial. Radiology 2002; 225: $27-34$

[43] Khan MA, Akbar A, Baron TH et al. Endoscopic ultrasound-guided biliary drainage: a systematic review and meta-analysis. Dig Dis Sci 2016; 61: 684-703

[44] Moole H, Bechtold ML, Forcione D et al. A meta-analysis and systematic review: Success of endoscopic ultrasound guided biliary stenting in patients with inoperable malignant biliary strictures and a failed ERCP. Medicine 2017; 96: e5154

[45] Wang K, Zhu J, Xing L et al. Assessment of efficacy and safety of EUSguided biliary drainage: a systematic review. Gastrointest Endosc 2016; 83: $1218-1227$

[46] Fabbri C, Luigiano C, Lisotti A et al. Endoscopic ultrasound-guided treatments: are we getting evidence based - a systematic review. World J Gastroenterol 2014; 20: 8424-8448

[47] Hara K, Yamao K, Hijioka S et al. Prospective clinical study of endoscopic ultrasound-guided choledochoduodenostomy with direct metallic stent placement using a forward-viewing echoendoscope. Endoscopy 2013; 45: $392-396$

[48] Kawakubo K, Kawakami H, Kuwatani M et al. Endoscopic ultrasoundguided choledochoduodenostomy vs. transpapillary stenting for distal biliary obstruction. Endoscopy 2016; 48: 164-169

[49] Moole H, Jaeger A, Cashman M et al. Are self-expandable metal stents superior to plastic stents in palliating malignant distal biliary strictures? A meta-analysis and systematic review Med J Armed Forces India 2017; 73: $42-48$

[50] Zorron PuL, de Moura EG, Bernardo WM et al. Endoscopic stenting for inoperable malignant biliary obstruction: A systematic review and meta-analysis. World J Gastroenterol 2015; 21: 13374-13385

[51] Hong WD, Chen XW, Wu WZ et al. Metal versus plastic stents for malignant biliary obstruction: an update meta-analysis. Clin Res Hepatol Gastroenterol 2013; 37: 496-500

[52] Almadi MA, Barkun A, Martel M. Plastic vs. self-expandable metal stents for palliation in malignant biliary obstruction: a series of metaanalyses. Am J Gastroenterol 2017; 112: 260 - 273

[53] Sawas T, Al Halabi S, Parsi MA et al. Self-expandable metal stents versus plastic stents for malignant biliary obstruction: a meta-analysis. Gastrointest Endosc 2015; 82: 256-267 e257

[54] Walter D, van Boeckel PGA, Groenen MJ et al. Cost efficacy of metal stents for palliation of extrahepatic bile duct obstruction in a randomized controlled trial. Gastroenterology 2015; 149: 130-138

[55] Walter D, van Boeckel PGA, Groenen MJM et al. Higher quality of life after metal stent placement compared with plastic stent placement for malignant extrahepatic bile duct obstruction: a randomized controlled trial. Eur J Gastroenterol Hepatol 2017; 29: 231 -237
[56] Chen M-Y, Lin J-W, Zhu H-P et al. Covered stents versus uncovered stents for unresectable malignant biliary strictures: a meta-analysis. Biomed Res Int 2016; 2016: 6408067

[57] Moole H, Bechtold ML, Cashman M et al. Covered versus uncovered self-expandable metal stents for malignant biliary strictures: A metaanalysis and systematic review. Indian J Gastroenterol 2016; 35: 323 330

[58] Li J, Li T, Sun P et al. Covered versus uncovered self-expandable metal stents for managing malignant distal biliary obstruction: a meta-analysis. PloS One 2016; 11: e0149066

[59] Alastal Y, Hammad T, Khan AM et al. Risk of post-ERCP pancreatitis with the placement of covered versus uncovered self-expandable biliary metal stents: systematic review and meta-analysis. JOP 2015; 16: $452-458$

[60] Saleem A, Leggett CL, Murad MH et al. Meta-analysis of randomized trials comparing the patency of covered and uncovered self-expandable metal stents for palliation of distal malignant bile duct obstruction. Gastrointest Endosc 2011; 74: 321-327 e321-323

[61] Almadi MA, Barkun AN, Martel M. No benefit of covered vs uncovered self-expandable metal stents in patients with malignant distal biliary obstruction: a meta-analysis. Clin Gastroenterol Hepatol 2013; 11: $27-37 . e 21$

[62] Yang Z, Wu Q, Wang F et al. A systematic review and meta-analysis of randomized trials and prospective studies comparing covered and bare self-expandable metal stents for the treatment of malignant obstruction in the digestive tract. Int J Med Sci 2013; 10: 825-835

[63] Fumex F, Coumaros D, Napoleon B et al. Similar performance but higher cholecystitis rate with covered biliary stents: results from a prospective multicenter evaluation. Endoscopy 2006; 38: 787-792

[64] Isayama H, Komatsu Y, Tsujino T et al. A prospective randomised study of "covered" versus "uncovered" diamond stents for the management of distal malignant biliary obstruction. Gut 2004; 53: 729 734

[65] Krokidis M, Fanelli F, Orgera G et al. Percutaneous treatment of malignant jaundice due to extrahepatic cholangiocarcinoma: covered Viabil stent versus uncovered Wallstents. Cardiovasc Intervent Radiol 2010; 33: $97-106$

[66] Isayama H, Mukai T, Itoi T et al. Comparison of partially covered nitinol stents with partially covered stainless stents as a historical control in a multicenter study of distal malignant biliary obstruction: the WATCH study. Gastrointest Endosc 2012; 76: 84-92

[67] Soderlund C, Linder S, Bergenzaun PE et al. Nitinol versus steel partially covered self-expandable metal stent for malignant distal biliary obstruction: a randomized trial. Endoscopy 2014; 46: 941 - 948

[68] Hu B, Wang TT, Wu J et al. Antireflux stents to reduce the risk of cholangitis in patients with malignant biliary strictures: a randomized trial. Endoscopy 2014; 46: $120-126$

[69] Lee YN, Moon JH, Choi HJ et al. Effectiveness of a newly designed antireflux valve metal stent to reduce duodenobiliary reflux in patients with unresectable distal malignant biliary obstruction: a randomized, controlled pilot study (with videos). Gastrointest Endosc 2016; 83: 404-412

[70] Zhang R, Luo H, Pan Y et al. Rate of duodenal-biliary reflux increases in patients with recurrent common bile duct stones: evidence from barium meal examination. Gastrointest Endosc 2015; 82: 660-665

[71] Park do H, Lee SS, Lee TH et al. Anchoring flap versus flared end, fully covered self-expandable metal stents to prevent migration in patients with benign biliary strictures: a multicenter, prospective, comparative pilot study (with videos). Gastrointest Endosc 2011; 73: 64-70

[72] Minaga K, Kitano M, Imai $\mathrm{H}$ et al. Evaluation of anti-migration properties of biliary covered self-expandable metal stents. World J Gastroenterol 2016; 22: 6917-6919

[73] Hamada T, Isayama H, Nakai Y et al. Antireflux metal stent with an antimigration system for distal malignant biliary obstruction: a feasi- 
bility pilot study. Surg Laparosc Endosc Percutan Tech 2015; 25: 212 217

[74] Zhu H-D, Guo J-H, Zhu G-Y et al. A novel biliary stent loaded with (125)I seeds in patients with malignant biliary obstruction: preliminary results versus a conventional biliary stent. J Hepatol 2012; 56: $1104-1111$

[75] Hasimu A, Gu J-P, Ji W-Z et al. Comparative study of percutaneous transhepatic biliary stent placement with or without iodine- 125 seeds for treating patients with malignant biliary obstruction. J Vasc Intervent Radiol 2017; 28: 583 - 593

[76] Jang SI, Lee SJ, Jeong $S$ et al. Efficacy of a multiplex paclitaxel emission stent using a Pluronic( $(\mathbb{B})$ mixture membrane versus a covered metal stent in malignant biliary obstruction: a prospective randomized comparative study. Gut Liver 2017; 11: 567 - 573

[77] Moole H, Bechtold ML, Cashman M et al. Are double-layer stents better than plastic stents and self-expandable metal stents in palliating malignant biliary obstruction? Meta-analysis and systematic review J Gastrointest Dig Syst 2016; 6: 1 -6

[78] Leong QW, Shen ML, Au KW et al. A prospective, randomized study of the patency period of the plastic antireflux biliary stent: an interim analysis. Gastrointest Endosc 2016; 83: 387-393

[79] Shatzel J, Kim J, Sampath K et al. Drug eluting biliary stents to decrease stent failure rates: A review of the literature. World J Gastrointest Endosc 2016; 8: $77-85$

[80] Khashab MA, Hutfless S, Kim K et al. A comparative evaluation of early stent occlusion among biliary conventional versus wing stents. Dig Dis Sci 2012; 57: $1708-1716$

[81] Wagh MS, de Bellis M, Fogel EL et al. Multicenter randomized trial of 10 -French versus 11.5 -French plastic stents for malignant biliary obstruction. Diagn Ther Endosc 2013; 2013: 891915 doi: 10.1155/ 2013/891915

[82] Wolfson D, Barkin JS, Chari ST et al. Management of pancreatic masses. Pancreas 2005; 31: $203-217$

[83] Siriwardana HP, Siriwardena AK. Systematic appraisal of the role of metallic endobiliary stents in the treatment of benign bile duct stricture. Ann Surg 2005; 242: $10-19$

[84] Arias Dachary FJ, Chioccioli C, Deprez PH. Application of the "coveredstent-in-uncovered-stent" technique for easy and safe removal of embedded biliary uncovered SEMS with tissue ingrowth. Endoscopy 2010; 42: (Suppl. 02): E304-305

[85] Tan DM, Lillemoe KD, Fogel EL. A new technique for endoscopic removal of uncovered biliary self-expandable metal stents: stentin-stent technique with a fully covered biliary stent. Gastrointest Endosc 2012; 75: $923-925$

[86] Tringali A, Blero D, Boskoski I et al. Difficult removal of fully covered self expandable metal stents (SEMS) for benign biliary strictures: the "SEMS in SEMS" technique. Dig Liv Dis 2014; 46: 568-571

[87] Zheng B, Wang X, Ma B et al. Endoscopic stenting versus gastrojejunostomy for palliation of malignant gastric outlet obstruction. Dig Endosc 2012; 24: 71 - 78

[88] Nagaraja V, Eslick GD, Cox MR. Endoscopic stenting versus operative gastrojejunostomy for malignant gastric outlet obstruction - a systematic review and meta-analysis of randomized and non-randomized trials. J Gastrointest Oncol 2014; 5: 92 - 98

[89] Hosono S, Ohtani H, Arimoto Y et al. Endoscopic stenting versus surgical gastroenterostomy for palliation of malignant gastroduodenal obstruction: a meta-analysis. J Gastroenterol 2007; 42: 283-290

[90] Bian S-B, Shen W-S, Xi H-Q et al. Palliative therapy for gastric outlet obstruction caused by unresectable gastric cancer: a meta-analysis comparison of gastrojejunostomy with endoscopic stenting. Chin Med J 2016; 129: 1113 - 1121
[91] Jeurnink SM, van Eijck CHJ, Steyerberg EW et al. Stent versus gastrojejunostomy for the palliation of gastric outlet obstruction: a systematic review. BMC Gastroenterol 2007; 7: 18

[92] Minata MK, Bernardo WM, Rocha RSdP et al. Stents and surgical interventions in the palliation of gastric outlet obstruction: a systematic review. Endosc Int Open 2016; 4: E1158-E1170

[93] Ly J, O'Grady G, Mittal A et al. A systematic review of methods to palliate malignant gastric outlet obstruction. Surg Endosc 2010; 24: $290-297$

[94] Chen Y-I, Itoi T, Baron TH et al. EUS-guided gastroenterostomy is comparable to enteral stenting with fewer re-interventions in malignant gastric outlet obstruction. Surg Endosc 2016; 230: 8-7

[95] Khashab MA, Bukhari M, Baron TH et al. International multicenter comparative trial of endoscopic ultrasonography-guided gastroenterostomy versus surgical gastrojejunostomy for the treatment of malignant gastric outlet obstruction. Endosc Int Open 2017; 5: E275-E281

[96] Matsumoto $\mathrm{K}$, Kato $\mathrm{H}$, Tsutsumi $\mathrm{K}$ et al. Long-term outcomes and risk factors of biliary stent dysfunction after endoscopic double stenting for malignant biliary and duodenal obstructions. Dig Endosc 2017; 29: $617-625$

[97] Jeurnink SM, Steyerberg EW, Vleggaar FP et al. Predictors of survival in patients with malignant gastric outlet obstruction: a patient-oriented decision approach for palliative treatment. Dig Liver Dis 2011; 43: $548-552$

[98] Mutignani M, Tringali A, Shah SG et al. Combined endoscopic stent insertion in malignant biliary and duodenal obstruction. Endoscopy 2007; 39: $440-447$

[99] Canena J, Coimbra J, Carvalho D et al. Endoscopic bilio-duodenal bypass: outcomes of primary and revision efficacy of combined metallic stents in malignant duodenal and biliary obstructions. Dig Dis Sci 2014; 59: 2779-2789

[100] Khashab MA, Valeshabad AK, Leung W et al. Multicenter experience with performance of ERCP in patients with an indwelling duodenal stent. Endoscopy 2014; 46: 252-255

[101] Davids PH, Groen AK, Rauws EA et al. Randomised trial of self-expanding metal stents versus polyethylene stents for distal malignant biliary obstruction. Lancet 1992; 340: 1488-1492

[102] Schmidt A, Riecken B, Rische S et al. Wing-shaped plastic stents vs. self-expandable metal stents for palliative drainage of malignant distal biliary obstruction: a randomized multicenter study. Endoscopy 2015; 47: 430-436

[103] Shah T, Desai S, Haque M et al. Management of occluded metal stents in malignant biliary obstruction: similar outcomes with second metal stents compared to plastic stents. Dig Dis Sci 2012; 57: $2765-2773$

[104] Lee BS, Ryu JK, Jang DK et al. Reintervention for occluded metal stent in malignant bile duct obstruction: A prospective randomized trial comparing covered and uncovered metal stent. J Gastroenterol Hepatol 2016; 31: $1901-1907$

[105] Kadayifci A, Atar M, Forcione DG et al. Radiofrequency ablation for the management of occluded biliary metal stents. Endoscopy 2016; 48: $1096-1101$

[106] Galandi D, Schwarzer G, Bassler D et al. Ursodeoxycholic acid and/or antibiotics for prevention of biliary stent occlusion. Cochrane Database Syst Rev 2002: CD003043 doi:10.1002/14651858

[107] Dumonceau J-M, Andriulli A, Elmunzer B] et al. Prophylaxis of postERCP pancreatitis: European Society of Gastrointestinal Endoscopy (ESGE) Guideline - Updated June 2014. Endoscopy 2014; 46: 799 815

[108] Patai Á, Solymosi N, Mohácsi L et al. Indomethacin and diclofenac in the prevention of post-ERCP pancreatitis: a systematic review and meta-analysis of prospective controlled trials. Gastrointest Endosc 2017; 85: 1144 -1156.e1141 
[109] Inamdar S, Han D, Passi M et al. Rectal indomethacin is protective against post-ERCP pancreatitis in high-risk patients but not averagerisk patients: a systematic review and meta-analysis. Gastrointest Endosc 2017; 85: $67-75$

[110] Barkin JA, Souto EO, Barkin JS. Rectal indomethacin should be used routinely in all patients for prevention of post-ERCP pancreatitis. Gastrointest Endosc 2017; 85: 687-688

[111] He X-K, Sun L-M. Does rectal indomethacin prevent post-ERCP pancreatitis in average-risk patients? Gastrointest Endosc 2017; 85: 687

[112] Inamdar S, Sejpal DV, Trindade AJ. Response. Gastrointest Endosc 2017; 85: 689-690

[113] Dumonceau J-M, Rigaux J, Kahaleh M et al. Prophylaxis of post-ERCP pancreatitis: a practice survey. Gastrointest Endosc 2010; 71 : 934 939 - 939.e931-932

[114] Hanna MS, Portal AJ, Dhanda AD et al. UK wide survey on the prevention of post-ERCP pancreatitis. Frontline Gastroenterol 2014; 5: $103-110$

[115] Motte S, Deviere J, Dumonceau JM et al. Risk factors for septicemia following endoscopic biliary stenting. Gastroenterology 1991; 101: $1374-1381$

[116] Allison MC, Sandoe JAT, Tighe R et al. Antibiotic prophylaxis in gastrointestinal endoscopy. Gut 2009; 58: 869-880

[117] Harris A, Chan AC, Torres-Viera C et al. Meta-analysis of antibiotic prophylaxis in endoscopic retrograde cholangiopancreatography (ERCP). Endoscopy 1999; 31: 718-724

[118] Khashab MA, Chithadi KV, Acosta RD et al. Antibiotic prophylaxis for Gl endoscopy. Gastrointest Endosc 2015; 81: 81 - 89

[119] Olsson G, Arnelo U, Lundell L et al. The role of antibiotic prophylaxis in routine endoscopic retrograde cholangiopancreatography investigations as assessed prospectively in a nationwide study cohort. Scand J Gastroenterol 2015; 50: 924-931

[120] Voiosu TA, Bengus A, Haidar A et al. Antibiotic prophylaxis prior to elective ERCP does not alter cholangitis rates or shorten hospital stay: results of an observational prospective study of 138 consecutive ERCPs. Maedica (Buchar) 2014; 9: 328-332

[121] Ishigaki T, Sasaki T, Serikawa M et al. Evaluation of antibiotic use to prevent post-endoscopic retrograde cholangiopancreatography pancreatitis and cholangitis. Hepatogastroenterology 2015; 62: $417-424$

[122] Wobser H, Gunesch A, Klebl F. Prophylaxis of post-ERC infectious complications in patients with biliary obstruction by adding antimicrobial agents into ERC contrast media - a single center retrospective study. BMC Gastroenterol 2017; 17: 10

[123] Cui P-J, Yao J, Zhao Y-J et al. Biliary stenting with or without sphincterotomy for malignant biliary obstruction: a meta-analysis. World ] Gastroenterol 2014; 20: 14033-14039

[124] Sofi AA, Nawras A, Alaradi OH et al. Does endoscopic sphincterotomy reduce the risk of post-ERCP pancreatitis after biliary stenting? A systematic review and meta-analysis Dig Endosc 2016; 28: 394 404

[125] Martins FP, Kahaleh M, Ferrari AP. Management of liver transplantation biliary stricture: Results from a tertiary hospital. World J Gastrointest Endosc 2015; 7: $747-757$

[126] Ekkelenkamp V, de Man R, Ter Borg F et al. Prospective evaluation of ERCP performance: results of a nationwide quality registry. Endoscopy 2015; 47: $503-507$

[127] Colan-Hernandez J, Aldana A, Concepción M et al. Optimal timing for a second ERCP after failure of initial biliary cannulation following precut sphincterotomy: an analysis of experience at two tertiary centers. Surg Endosc 2017; 31: 125

[128] Donnellan F, Enns R, Kim E et al. Outcome of repeat ERCP after initial failed use of a needle knife for biliary access. Dig Dis Sci 2012; 57: $1069-1071$
[129] Hisai H, Okagawa Y, Wada H et al. Outcome of repeat ERCP after biliary cannulation failure following needle knife sphincterotomy. Gastrointest Endosc 2013; 77: AB291

[130] Kevans D, Zeb F, Donnellan F et al. Failed biliary access following needle knife fistulotomy: is repeat interval ERCP worthwhile? Scand ] Gastroenterol 2010; 45: 1238-1241

[131] Kim J, Ryu JK, Ahn D-W et al. Results of repeat endoscopic retrograde cholangiopancreatography after initial biliary cannulation failure following needle-knife sphincterotomy. J Gastroenterol Hepatol 2012; 27: 516- 520

[132] Pavlides M, Barnabas A, Fernandopulle N et al. Repeat endoscopic retrograde cholangiopancreaticography after failed initial precut sphincterotomy for biliary cannulation. World J Gastroenterol 2014; 20: $13153-13158$

[133] Ramirez FC, Dennert B, Sanowski RA. Success of repeat ERCP by the same endoscopist. Gastrointest Endosc 1999; 49: 58 -61

[134] Testoni P-A, Mariani A, Aabakken L et al. Papillary cannulation and sphincterotomy techniques at ERCP: European Society of Gastrointestinal Endoscopy (ESGE) Clinical Guideline. Endoscopy 2016; 48: $657-683$

[135] Baniya R, Upadhaya S, Madala S et al. Endoscopic ultrasound-guided biliary drainage versus percutaneous transhepatic biliary drainage after failed endoscopic retrograde cholangiopancreatography: a meta-analysis. Clin Exp Gastroenterol 2017; 10: 67-74

[136] Sportes A, Camus M, Greget M et al. Endoscopic ultrasound-guided hepaticogastrostomy versus percutaneous transhepatic drainage for malignant biliary obstruction after failed endoscopic retrograde cholangiopancreatography: a retrospective expertise-based study from two centers. Therap Adv Gastroenterol 2017; 10: 483-493

[137] Artifon ELA, Loureiro JF, Baron TH et al. Surgery or EUS-guided choledochoduodenostomy for malignant distal biliary obstruction after ERCP failure. Endosc Ultrasound 2015; 4: 235-243

[138] Tonozuka R, Itoi T, Tsuchiya T et al. EUS-guided biliary drainage is infrequently used even in high-volume centers of interventional EUS. Gastrointest Endosc 2016; 84: $206-207$

[139] Holt BA, Hawes R, Hasan M et al. Biliary drainage: role of EUS guidance. Gastrointest Endosc 2016; 83: 160-165

[140] Oh D, Park DH, Song TJ et al. Optimal biliary access point and learning curve for endoscopic ultrasound-guided hepaticogastrostomy with transmural stenting. Therap Adv Gastroenterol 2017; 10: 42 53

[141] Ogura T, Chiba Y, Masuda D et al. Comparison of the clinical impact of endoscopic ultrasound-guided choledochoduodenostomy and hepaticogastrostomy for bile duct obstruction with duodenal obstruction. Endoscopy 2016; 48: 163

[142] Artifon EL, Furuya CK, Cunha MAB et al. Metal or plastic stents to EUS-guided choledocho-duodenostomy: a prospective trial. Gastrointest Endosc 2015; 81: AB175

[143] Poincloux L, Rouquette O, Buc E et al. Endoscopic ultrasound-guided biliary drainage after failed ERCP: cumulative experience of 101 procedures at a single center. Endoscopy 2015; 47: $794-801$

[144] Song T], Lee SS, Park do $\mathrm{H}$ et al. Preliminary report on a new hybrid metal stent for EUS-guided biliary drainage (with videos). Gastrointest Endosc 2014; 80: 707-711

[145] Park DH, Lee TH, Paik WH et al. Feasibility and safety of a novel dedicated device for one-step EUS-guided biliary drainage: A randomized trial. J Gastroenterol Hepatol 2015; 30: 1461 - 1466

[146] Cho DH, Lee SS, Oh D et al. Long-term outcomes of a newly developed hybrid metal stent for EUS-guided biliary drainage (with videos). Gastrointest Endosc 2017; 85: 1067 - 1075

[147] Kunda R, Pérez-Miranda M, Will U et al. EUS-guided choledochoduodenostomy for malignant distal biliary obstruction using a 
lumen-apposing fully covered metal stent after failed ERCP. Surg Endosc 2016; 30: $5002-5008$

[148] Zhang H, Zhu J, Ke F et al. Radiological imaging for assessing the resectability of hilar cholangiocarcinoma: a systematic review and meta-analysis. Biomed Res Int 2015; 2015: 497942

[149] Elias Y, Mariano AT, Lu Y. Detection of primary malignancy and metastases with FDG PET/CT in patients with cholangiocarcinomas: lesion-based comparison with contrast enhanced CT. World J Nucl Med 2016; 15: 161 - 166

[150] Ryoo I, Lee JM, Park HS et al. Preoperative assessment of longitudinal extent of bile duct cancers using MDCT with multiplanar reconstruction and minimum intensity projections: comparison with MR cholangiography. Eur J Radiol 2012; 81: 2020-2026

[151] Wu X-P, Ni J-M, Zhang Z-Y et al. Preoperative evaluation of malignant perihilar biliary obstruction: negative-contrast CT cholangiopancreatography and $C T$ angiography versus MRCP and MR angiography. AJR Am J Roentgenol 2015; 205: $780-788$

[152] Mansour JC, Aloia TA, Crane CH et al. Hilar cholangiocarcinoma: expert consensus statement. HPB (Oxford) 2015; 17: 691-699

[153] Muggli D, Muller MA, Karlo C et al. A simple method to approximate liver size on cross-sectional images using living liver models. Clin Radiol 2009; 64: 682-689

[154] Lim MC, Tan CH, Cai J et al. CT volumetry of the liver: where does it stand in clinical practice? Clin Radiol 2014; 69: 887-895

[155] Keswani RN, Qumseya BJ, O’Dwyer LC et al. Association between endoscopist and center endoscopic retrograde cholangiopancreatography volume with procedure success and adverse outcomes: a systematic review and meta-analysis. Clin Gastroenterol Hepatol 2017; 15: 1866 - 1875.e3

[156] Ekkelenkamp VE, de Man RA, Ter Borg F et al. Prospective evaluation of ERCP performance: results of a nationwide quality registry. Endoscopy 2015; 47: 503-507

[157] Paik WH, Park YS, Hwang JH et al. Palliative treatment with self-expandable metallic stents in patients with advanced type III or IV hilar cholangiocarcinoma: a percutaneous versus endoscopic approach. Gastrointest Endosc 2009; 69: 55-62

[158] Coelen RJ, Huiskens ], Olthof PB et al. Compliance with evidencebased multidisciplinary guidelines on perihilar cholangiocarcinoma. United European Gastroenterol J 2017; 5: 519-526

[159] Liu F, Li Y, Wei Y et al. Preoperative biliary drainage before resection for hilar cholangiocarcinoma: whether or not? A systematic review Dig Dis Sci 2011; 56: 663-672

[160] Celotti A, Solaini L, Montori G et al. Preoperative biliary drainage in hilar cholangiocarcinoma: Systematic review and meta-analysis. Eur J Surg Oncol 2017; 43: 1628-1635

[161] Wiggers JK, Groot Koerkamp B, Cieslak KP et al. Postoperative mortality after liver resection for perihilar cholangiocarcinoma: development of a risk score and importance of biliary drainage of the future liver remnant. J Am Coll Surg 2016; 223: 321 - 331.e321

[162] Olthof PB, Wiggers JK, Koerkamp BG et al. Postoperative liver failure risk score: identifying patients with resectable perihilar cholangiocarcinoma who may benefit from portal vein embolization. J Am Coll Surg 2017; 225: $387-394$

[163] Hameed A, Pang T, Chiou J et al. Percutaneous vs. endoscopic preoperative biliary drainage in hilar cholangiocarcinoma - a systematic review and meta-analysis. HPB (Oxford) 2016; 18: 400 -410

[164] Al Mahjoub A, Menahem B, Fohlen A et al. Preoperative biliary drainage in patients with resectable perihilar cholangiocarcinoma: is percutaneous transhepatic biliary drainage safer and more effective than endoscopic biliary drainage? A meta-analysis J Vasc Intervent Radiol: JVIR 2017; 28: 576-582
[165] Kishi Y, Shimada K, Nara S et al. The type of preoperative biliary drainage predicts short-term outcome after major hepatectomy. Langenbecks Arch Surg 2016; 401: 503 - 511

[166] Komaya K, Ebata T, Yokoyama Y et al. Verification of the oncologic inferiority of percutaneous biliary drainage to endoscopic drainage: A propensity score matching analysis of resectable perihilar cholangiocarcinoma. Surgery 2017; 161: $394-404$

[167] Hirano S, Tanaka E, Tsuchikawa T et al. Oncological benefit of preoperative endoscopic biliary drainage in patients with hilar cholangiocarcinoma. J Hepatobiliary Pancreat Sci 2014; 21: 533 - 540

[168] Ebata T, Mizuno T, Yokoyama Y et al. Surgical resection for Bismuth type IV perihilar cholangiocarcinoma. Br J Surg 2018; 105: 829-838

[169] Takahashi Y, Nagino M, Nishio H et al. Percutaneous transhepatic biliary drainage catheter tract recurrence in cholangiocarcinoma. Br J Surg 2010; 97: 1860 - 1866

[170] Wiggers JK, Groot Koerkamp B, Coelen RJ et al. Percutaneous preoperative biliary drainage for resectable perihilar cholangiocarcinoma: no association with survival and no increase in seeding metastases. Ann Surg Oncol 2015; 22: (Suppl. 03): S1156-1163

[171] Kawashima H, Itoh A, Ohno E et al. Preoperative endoscopic nasobiliary drainage in 164 consecutive patients with suspected perihilar cholangiocarcinoma: a retrospective study of efficacy and risk factors related to complications. Ann Surg 2013; 257: 121 - 127

[172] Kawakami H, Kuwatani M, Onodera M et al. Endoscopic nasobiliary drainage is the most suitable preoperative biliary drainage method in the management of patients with hilar cholangiocarcinoma. J Gastroenterol 2011; 46: 242-248

[173] Grünhagen D], Dunne DF], Sturgess RP et al. Metal stents: a bridge to surgery in hilar cholangiocarcinoma. HPB (Oxford) 2013; 15: 372 378

[174] Moole H, Dharmapuri S, Duvvuri A et al. Endoscopic versus percutaneous biliary drainage in palliation of advanced malignant hilar obstruction: a meta-analysis and systematic review. Can J Gastroenterol Hepatol 2016: doi:10.1155/2016/4726078

[175] Gamanagatti S, Singh T, Sharma R. Unilobar versus bilobar biliary drainage: effect on quality of life and bilirubin level reduction. Indian J Palliat Care 2016; 22: 50-62

[176] Barkay O, Mosler P, Schmitt CM et al. Effect of endoscopic stenting of malignant bile duct obstruction on quality of life. J Clin Gastroenterol 2013; 47: 526-531

[177] Saluja SS, Gulati M, Garg PK et al. Endoscopic or percutaneous biliary drainage for gallbladder cancer: a randomized trial and quality of life assessment. Clin Gastroenterol Hepatol 2008; 6: 944-950.e943

[178] Roos E, Coelen RJS, Wiggers JK et al. Preoperative endoscopic versus percutaneous transhepatic biliary drainage in resectable perihilar cholangiocarcinoma: a multicenter randomized controlled trial. UEG J 2017; 5: A130

[179] Jang SI, Hwang J-H, Lee K-H et al. Percutaneous biliary approach as a successful rescue procedure after failed endoscopic therapy for drainage in advanced hilar tumors. J Gastroenterol Hepatol 2017; 32: $932-938$

[180] Takahashi E, Fukasawa M, Sato T et al. Biliary drainage strategy of unresectable malignant hilar strictures by computed tomography volumetry. World J Gastroenterol 2015; 21: 4946-4953

[181] Bulajic M, Panic N, Radunovic M et al. Clinical outcome in patients with hilar malignant strictures type II Bismuth-Corlette treated by minimally invasive unilateral versus bilateral endoscopic biliary drainage. Hepatobiliary Pancreat Dis Int 2012; 11: 209-214

[182] Vienne A, Hobeika E, Gouya H et al. Prediction of drainage effectiveness during endoscopic stenting of malignant hilar strictures: the role of liver volume assessment. Gastrointest Endosc 2010; 72: $728-735$ 
[183] Puli SR, Kalva N, Pamulaparthy SR et al. Bilateral and unilateral stenting for malignant hilar obstruction: a systematic review and meta-analysis. Indian J Gastroenterol 2013; 32: 355-362

[184] Hong W, Sun X, Zhu Q. Endoscopic stenting for malignant hilar biliary obstruction: should it be metal or plastic and unilateral or bilateral? Eur J Gastroenterol Hepatol 2013; 25: 1105-1112

[185] Lee TH, Kim TH, Moon JH et al. Bilateral versus unilateral placement of metal stents for inoperable high-grade malignant hilar biliary strictures: a multicenter, prospective, randomized study (with video). Gastrointest Endosc 2017; 86: 817-827

[186] Chang WH, Kortan P, Haber GB. Outcome in patients with bifurcation tumors who undergo unilateral versus bilateral hepatic duct drainage. Gastrointest Endosc 1998; 47: 354- 362

[187] Deviere J, Baize M, de Toeuf J et al. Long-term follow-up of patients with hilar malignant stricture treated by endoscopic internal biliary drainage. Gastrointest Endosc 1988; 34: 95-101

[188] Yasuda I, Mukai T, Moriwaki H. Unilateral versus bilateral endoscopic biliary stenting for malignant hilar biliary strictures. Dig Endosc 2013; 25: (Suppl. 02): $81-85$

[189] Singh V, Singh G, Verma GR et al. Contrast-free unilateral endoscopic palliation in malignant hilar biliary obstruction: new method. J Gastroenterol Hepatol 2004; 19: 589-592

[190] Sud R, Puri R, Choudhary NS et al. Air cholangiogram is not inferior to dye cholangiogram for malignant hilar biliary obstruction: a randomized study of efficacy and safety. Indian J Gastroenterol 2014; 33: $537-542$

[191] Zhang R, Zhao L, Liu Z et al. Effect of CO2 cholangiography on postERCP cholangitis in patients with unresectable malignant hilar obstruction - a prospective, randomized controlled study. Scand ] Gastroenterol 2013; 48: $758-763$

[192] Lee JM, Lee SH, Jang DK et al. Air cholangiography in endoscopic bilateral stent-in-stent placement of metallic stents for malignant hilar biliary obstruction. Therap Adv Gastroenterol 2016; 9: 189-198

[193] Pisello F, Geraci G, Modica G et al. Cholangitis prevention in endoscopic Klatskin tumor palliation: air cholangiography technique. Langenbecks Arch Surg 2009; 394: 1109-1114

[194] Hintze RE, Abou-Rebyeh H, Adler A et al. Magnetic resonance cholangiopancreatography-guided unilateral endoscopic stent placement for Klatskin tumors. Gastrointest Endosc 2001; 53: 40 - 46

[195] Freeman ML, Overby C. Selective MRCP and CT-targeted drainage of malignant hilar biliary obstruction with self-expanding metallic stents. Gastrointest Endosc 2003; 58: 41 - 49

[196] Mukai T, Yasuda I, Nakashima M et al. Metallic stents are more efficacious than plastic stents in unresectable malignant hilar biliary strictures: a randomized controlled trial. J Hepatobiliary Pancreat Sci 2013; 20: $214-222$

[197] Sangchan A, Chaiyakunapruk N, Supakankunti S et al. Cost utility analysis of endoscopic biliary stent in unresectable hilar cholangiocarcinoma: decision analytic modeling approach. Hepatogastroenterology 2014; 61: 1175-1181

[198] Gao D], Hu B, Ye X et al. Metal versus plastic stents for unresectable gallbladder cancer with hilar duct obstruction. Dig Endosc 2017; 29: $97-103$

[199] Inoue T, Okumura F, Naitoh I et al. Feasibility of the placement of a novel 6-mm diameter threaded fully covered self-expandable metal stent for malignant hilar biliary obstructions (with videos). Gastrointest Endosc 2016; 84: $352-357$

[200] Ayaru L, Kurzawinski TR, Shankar A et al. Complications and diagnostic difficulties arising from biliary self-expanding metal stent insertion before definitive histological diagnosis. J Gastroenterol Hepatol 2008; 23: $315-320$

[201] Hong W, Chen S, Zhu Q et al. Bilateral stenting methods for hilar biliary obstructions. Clinics (Sao Paulo) 2014; 69: 647-652
[202] Inoue T, Ishii N, Kobayashi Y et al. Simultaneous versus sequential side-by-side bilateral metal stent placement for malignant hilar biliary obstructions. Dig Dis Sci 2017; 62: 2542-2549

[203] Fujii M, Kawamoto H, Tsutsumi K et al. Management of occluded metallic stents in malignant hilar biliary stricture. Hepatogastroenterology 2013; 60: 447-451

[204] Inoue T, Naitoh I, Okumura F et al. Reintervention for stent occlusion after bilateral self-expandable metallic stent placement for malignant hilar biliary obstruction. Dig Endosc 2016; 28: 731 - 737

[205] Kadayifci A, Atar M, Forcione DG et al. Radiofrequency ablation for the management of occluded biliary metal stents. Endoscopy 2016; 48: $1096-1101$

[206] Györi GP, Schwarzer R, Püspök A et al. Endoscopic versus surgical management of biliary complications - Outcome analysis after 1188 orthotopic liver transplantations. Dig Liver Dis 2016; 48: 1323 1329

[207] Regimbeau J-M, Fuks D, Bartoli E et al. A comparative study of surgery and endoscopy for the treatment of bile duct stricture in patients with chronic pancreatitis. Surg Endosc 2012; 26: 2902 - 2908

[208] Fatima J, Barton JG, Grotz TE et al. Is there a role for endoscopic therapy as a definitive treatment for post-laparoscopic bile duct injuries? J Am Coll Surg 2010; 211: 495-502

[209] Coté GA, Slivka A, Tarnasky P et al. Effect of covered metallic stents compared with plastic stents on benign biliary stricture resolution: a randomized clinical trial. JAMA 2016; 315: $1250-1257$

[210] van Boeckel PG, Vleggaar FP, Siersema PD. Plastic or metal stents for benign extrahepatic biliary strictures: a systematic review. BMC Gastroenterol 2009; 9: 96

[211] Nguyen-Tang T, Dumonceau JM. Endoscopic treatment in chronic pancreatitis, timing, duration and type of intervention. Best Pract Res Clin Gastroenterol 2010; 24: 281 - 298

[212] Huszár O, Kokas B, Mátrai P et al. Meta-analysis of the long term success rate of different interventions in benign biliary strictures. PLoS One 2017; 12: e0169618

[213] Khan MA, Baron TH, Kamal F et al. Efficacy of self-expandable metal stents in management of benign biliary strictures and comparison with multiple plastic stents: a meta-analysis. Endoscopy 2017; 49: $682-694$

[214] Kaffes A, Griffin S, Vaughan R et al. A randomized trial of a fully covered self-expandable metallic stent versus plastic stents in anastomotic biliary strictures after liver transplantation. Therap Adv Gastroenterol 2014; 7: 64-71

[215] Martins FP, de Paulo GA, Contini MLC et al. Metal versus plastic stents for anastomotic biliary strictures after liver transplantation: a randomized controlled trial. Gastrointest Endosc 2018: doi:10.1016/j.gie.2017.04.013

[216] Costamagna G, Tringali A, Mutignani M et al. Endotherapy of postoperative biliary strictures with multiple stents: results after more than 10 years of follow-up. Gastrointest Endosc 2010; 72: 551-557

[217] Jang SI, Sung SY, Park H et al. Salvage therapy using self-expandable metal stents for recalcitrant anastomotic strictures after living-donor liver transplantation. Therap Adv Gastroenterol 2017; 10: 297 309

[218] Costamagna G, Pandolfi M, Mutignani M et al. Long-term results of endoscopic management of postoperative bile duct strictures with increasing numbers of stents. Gastrointest Endosc 2001; 54: 162 168

[219] Lawrence C, Romagnuolo J, Payne KM et al. Low symptomatic premature stent occlusion of multiple plastic stents for benign biliary strictures: comparing standard and prolonged stent change intervals. Gastrointest Endosc 2010; 72: $558-563$ 
[220] Morelli G, Fazel A, Judah ] et al. Rapid-sequence endoscopic management of posttransplant anastomotic biliary strictures. Gastrointest Endosc 2008; 67: 879-885

[221] Draganov P, Hoffman B, Marsh W et al. Long-term outcome in patients with benign biliary strictures treated endoscopically with multiple stents. Gastrointest Endosc 2002; 55: 680-686

[222] Kuzela L, Oltman M, Sutka J et al. Prospective follow-up of patients with bile duct strictures secondary to laparoscopic cholecystectomy, treated endoscopically with multiple stents. Hepatogastroenterology 2005; 52: 1357 - 1361

[223] Parlak E, Disibeyaz S, Odemiş B et al. Endoscopic treatment of patients with bile duct stricture after cholecystectomy: factors predicting recurrence in the long term. Dig Dis Sci 2015; 60: 1778 1786

[224] Behm B, Brock A, Clarke BW et al. Partially covered self-expandable metallic stents for benign biliary strictures due to chronic pancreatitis. Endoscopy 2009; 41: 547 - 551

[225] Cantù P, Hookey LC, Morales A et al. The treatment of patients with symptomatic common bile duct stenosis secondary to chronic pancreatitis using partially covered metal stents: a pilot study. Endoscopy 2005; 37: $735-739$

[226] Chaput U, Scatton O, Bichard P et al. Temporary placement of partially covered self-expandable metal stents for anastomotic biliary strictures after liver transplantation: a prospective, multicenter study. Gastrointest Endosc 2010; 72: 1167 - 1174

[227] Kao D, Zepeda-Gomez S, Tandon P et al. Managing the post-liver transplantation anastomotic biliary stricture: multiple plastic versus metal stents: a systematic review. Gastrointest Endosc 2013; 77: $679-691$

[228] Zheng X, Wu J, Sun B et al. Clinical outcome of endoscopic covered metal stenting for resolution of benign biliary stricture: Systematic review and meta-analysis. Dig Endosc 2017; 29: 198-210

[229] Kahaleh M, Brijbassie A, Sethi A et al. Multicenter trial evaluating the use of covered self-expanding metal stents in benign biliary strictures: time to revisit our therapeutic options? J Clin Gastroenterol 2013; 47: 695-699

[230] Deviere J, Nageshwar Reddy D, Puspok A et al. Successful management of benign biliary strictures with fully covered self-expanding metal stents. Gastroenterology 2014; 147: 385 - 395; quiz e315

[231] Blero D, Huberty V, Deviere J. Novel biliary self-expanding metal stents: indications and applications. Expert Rev Gastroenterol Hepatol 2015; 9: $359-367$

[232] Mahajan A, Ho H, Sauer B et al. Temporary placement of fully covered self-expandable metal stents in benign biliary strictures: midterm evaluation (with video). Gastrointest Endosc 2009; 70: 303 309

[233] Kasher JA, Corasanti JG, Tarnasky PR et al. A multicenter analysis of safety and outcome of removal of a fully covered self-expandable metal stent during ERCP. Gastrointest Endosc 2011; 73: 1292 - 1297

[234] Haapamaki C, Kylanpaa L, Udd M et al. Randomized multicenter study of multiple plastic stents vs. covered self-expandable metallic stent in the treatment of biliary stricture in chronic pancreatitis. Endoscopy 2015; 47: 605-610

[235] Eickhoff A, Jakobs R, Leonhardt A et al. Endoscopic stenting for common bile duct stenoses in chronic pancreatitis: results and impact on long-term outcome. Eur J Gastroenterol Hepatol 2001; 13: $1161-1167$

[236] Siiki A, Helminen M, Sand J et al. Covered self-expanding metal stents may be preferable to plastic stents in the treatment of chronic pancreatitis-related biliary strictures: a systematic review comparing 2 methods of stent therapy in benign biliary strictures. J Clin Gastroenterol 2014; 48: 635-643

[237] Pozsar ], Sahin P, Laszlo F et al. Medium-term results of endoscopic treatment of common bile duct strictures in chronic calcifying pan- creatitis with increasing numbers of stents. J Clin Gastroenterol 2004; 38: $118-123$

[238] Aparício DPDS, Otoch JP, Montero EFS et al. Endoscopic approach for management of biliary strictures in liver transplant recipients: A systematic review and meta-analysis. United European Gastroenterol j 2016; 5: $827-845$

[239] Macias Gomez C, Dumonceau J-M. Endoscopic management of biliary complications after liver transplantation: An evidence-based review. World J Gastrointest Endosc 2015; 7: 606-616

[240] Macias Gomez C, Dumonceau J-M, Marcolongo M et al. Endoscopic management of biliary complications after adult living-donor versus deceased-donor liver transplantation. Transplantation 2009; 88: $1280-1285$

[241] Rao HB, Ahamed H, Panicker S et al. Endoscopic therapy for biliary strictures complicating living donor liver transplantation: Factors predicting better outcome. World J Gastrointest Pathophysiol 2017; $8: 77-86$

[242] Tal AO, Finkelmeier F, Filmann N et al. Multiple plastic stents versus covered metal stent for treatment of anastomotic biliary strictures after liver transplantation: a prospective, randomized, multicenter trial. Gastrointest Endosc 2017; 86: 1038 - 1045

[243] Lee DW, Jo HH, Abdullah J et al. Endoscopic management of anastomotic strictures after liver transplantation. Clin Endosc 2016; 49: $457-461$

[244] Artifon EL, Coelho F, Frazao M et al. A prospective randomized study comparing partially covered metal stent versus plastic multistent in the endoscopic management of patients with postoperative benign bile duct strictures: a follow-up above 5 years. Rev Gastroenterol Peru 2012; 32: 26-31

[245] Coté GA. Metallic vs plastic stents for benign biliary strictures Reply. JAMA 2016; 316: 540 - 541

[246] Landi R, Tringali A, Boskoski I et al. Mo1343 Multiple plastic stents to treat post-cholecystectomy biliary strictures: 20 year experience on 183 patients. Gastrointest Endosc 2012; 75: AB395

[247] Adler DG, Papachristou GI, Taylor L] et al. Clinical outcomes in patients with bile leaks treated via ERCP with regard to the timing of ERCP: a large multicenter study. Gastrointest Endosc 2017; 85: $766-772$

[248] Dolay K, Soylu A, Aygun E. The role of ERCP in the management of bile leakage: endoscopic sphincterotomy versus biliary stenting. J Laparoendosc Adv Surg Tech A 2010; 20: 455 - 459

[249] Mavrogiannis C, Liatsos C, Papanikolaou IS et al. Biliary stenting alone versus biliary stenting plus sphincterotomy for the treatment of post-laparoscopic cholecystectomy biliary leaks: a prospective randomized study. Eur ] Gastroenterol Hepatol 2006; 18: 405-409

[250] Katsinelos P, Kountouras ], Paroutoglou G et al. A comparative study of 10-Fr vs. 7-Fr straight plastic stents in the treatment of postcholecystectomy bile leak. Surg Endosc 2008; 22: 101 - 106

[251] Canena J, Liberato M, Meireles L et al. A non-randomized study in consecutive patients with postcholecystectomy refractory biliary leaks who were managed endoscopically with the use of multiple plastic stents or fully covered self-expandable metal stents (with videos). Gastrointest Endosc 2015; 82: 70 - 78

[252] Langerth A, Sandblom G, Karlson B-M. Long-term risk for acute pancreatitis, cholangitis, and malignancy more than 15 years after endoscopic sphincterotomy: a population-based study. Endoscopy 2015; 47: $1132-1136$

[253] Farhat S, Bourrier A, Gaudric M et al. Endoscopic treatment of biliary fistulas after complex liver resection. Ann Surg 2011; 253: 88-93

[254] Parlak E, Disibeyaz S, Odemiş B et al. Endoscopic treatment of biliary fistulas developing after liver resections. Surg Laparosc Endosc Percutan Tech 2013; 23: $453-458$ 
[255] Tonozuka R, Itoi T, Tsuchiya T et al. EUS-guided drainage of hepatic abscess and infected biloma using short and long metal stents (with videos). Gastrointest Endosc 2015; 81: 1463 - 1469

[256] Ogura T, Masuda D, Saori O et al. Clinical outcome of endoscopic ultrasound-guided liver abscess drainage using self-expandable covered metallic stent (with video). Dig Dis Sci 2016; 61: 303-308

[257] Tonozuka R, Itoi T. Response. Gastrointest Endosc 2015; 82: 972 973

[258] Petrone M-C, Arcidiacono PG. EUS-guided drainage of liver abscesses: ultra uncertain or sound practice? Dig Dis Sci 2016; 61: 8-10

[259] Mohammed N, Pinder M, Harris K. Endoscopic biliary stenting in irretrievable common bile duct stones: stent exchange or expectant management - tertiary-centre experience and systematic review. Frontline Gastroenterol 2016; 7: 176-186

[260] Chopra KB, Peters RA, O'Toole PA et al. Randomised study of endoscopic biliary endoprosthesis versus duct clearance for bileduct stones in high-risk patients. Lancet 1996; 348: 791 - 793

[261] Di Giorgio P, Manes G, Grimaldi E et al. Endoscopic plastic stenting for bile duct stones: stent changing on demand or every 3 months. A prospective comparison study. Endoscopy 2013; 45: 1014-1017
[262] Ye X, Huai J, Sun X. Effectiveness and safety of biliary stenting in the management of difficult common bile duct stones in elderly patients. Turk J Gastroenterol 2016; 27: 30 - 36

[263] Hartery K, Cullen G, Mulcahy HE. Response. Gastrointest Endosc 2017; 86: $746-747$

[264] Pisello F, Geraci G, Li Volsi F et al. Permanent stenting in "unextractable" common bile duct stones in high risk patients. A prospective randomized study comparing two different stents. Langenbecks Arch Surg 2008; 393: 857-863

[265] Ooi M, Liu K, Sanagapalli S et al. The effects of a biliary stent registry on complications related to biliary stenting. Gastrointest Endosc 2015; 81: АB398

[266] Gu Y, Wang L, Zhao L et al. Effect of mobile phone reminder messages on adherence of stent removal or exchange in patients with benign pancreaticobiliary diseases: a prospectively randomized, controlled study. BMC Gastroenterol 2016; 16: 105 